\title{
Collinear Analysis of Altimeter Data in the Bering Sea
}

\author{
by
}

\section{Deborah Klatt Barber}

\author{
B.S., United States Naval Academy (1987) \\ Submitted in partial fulfillment of the \\ requirements for the degree of
}

MASTER OF SCIENCE IN PHYSICAL OCEANOGRAPHY at the

MASSACHUSETTS INSTITUTE OF TECHNOLOGY

and the

WOODS HOLE OCEANOGRAPHIC INSTITUTION

\begin{tabular}{|c|}
\hline MARINE \\
BIOLOGICAL \\
LABORATORY \\
\hline LIBRARY \\
\hline $\begin{array}{c}\text { WOODS HOLE, MASS. } \\
\text { W. H. O. I. }\end{array}$ \\
\hline
\end{tabular}

September 1989

(c) Deborah K. Barber, 1989

The author hereby grants to MIT and WHOI permission to reproduce and to distribute copies of this thesis document in whole or in part.

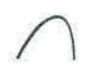

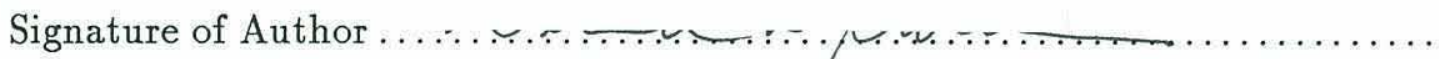

Joint Program in Physical Oceanography Massachusetts Institute of Technology

Woods Hole Oceanographic Institution August 11, 1989

Certified by Dr. Kathryn Kelly Woods Hole Oceanographic Institution I n Theșis Supervisor

Accepted by 


\title{
Collinear Analysis of Altimeter Data in the Bering Sea
}

\author{
by \\ Deborah Klatt Barber \\ Submitted to the Massachusetts Institute of Technology- \\ Woods Hole Oceanographic Institution \\ Joint Program in Physical Oceanography \\ on August 11, 1989, in partial fulfillment of the \\ requirements for the degree of \\ MASTER OF SCIENCE IN PHYSICAL OCEANOGRAPHY
}

\begin{abstract}
Eighteen months of sea surface height data from the GEOSAT altimeter along collinear subtracks were analyzed for information on the circulation pattern in the Bering Sea. Seventy subtracks from both ascending and descending orbits, with as many as 35 repeat cycles along each subtrack, were analyzed. Orbit errors were removed from the height data using a least-squares fit to a cubic polynomial, weighted by the inverse of the height variance. Addition of the weights decreased contamination of residual height profiles by the large geoid signal. Composite maps of variability along each track revealed patterns of increased variability in the regions of the documented Bering slope current (BSC) and the proposed western boundary current (WBC); however, no evidence was found of the expected bifurcation of the BSC near the Siberian coast. Past observations of tides in the Bering Sea were reviewed along with a local tide model to detect tidal contributions to the mesoscale sea surface height variability. The tidal analysis suggested that residual tides contributed primarily to the longer wavelengths which were removed in the collinear processing. Examination of the Schwiderski tidal correction proved it to be a sensible correction, reducing the height variance by approximately $60 \%$. Finally, using a Gaussian model for the BSC velocity profile, synthetic residual heights were generated and fit to the actual data to produce estimates of absolute surface geostrophic velocity and transport. Comparisons of mean flow, height fluctuations and seasonal trends across the BSC, the WBC and Bering Strait support the hypothesis that the BSC turns north at Cape Navarin into the WBC which, in turn, is capable of supplying a major part of the transport through the Bering Strait.
\end{abstract}

Thesis Supervisor: Dr. Kathryn Kelly

Woods Hole Oceanographic Institution 
I would like to thank the following people for their contributions to my thesis:

My advisor, Dr. Kathryn Kelly, for her guidance, insight and willingness to make time for me.

Mike Caruso, for enduring numerous questions, and providing the solutions to all my programming needs.

The U.S. Navy and Naval Postgraduate school for supporting the Joint program and allowing me to participate in it.

My family, for their patience and support.

Our Heavenly Father, who blessed me with all of the above. 


\section{Contents}

1 Introduction $\quad 10$

1.1 Background Oceanography .................... 11

1.2 Introduction to Satellite Altimetry . . . . . . . . . . . . 13

2 Data 16

2.1 GEOSAT Exact Repeat Mission . . . . . . . . . . . . 16

2.2 Altimeter Corrections . . . . . . . . . . . . . . . . . 17

2.3 Terminology . . . . . . . . . . . . . . . . . . . . . . . 23

2.4 Data Characteristics ... . . . . . . . . . . . . 23

3 Method of Analysis $\quad 30$

3.1 Collinear Processing Techniques . . . . . . . . . . . . . . . 30

3.2 Collinear Processing Algorithm . . . . . . . . . . . . . . . 32

3.3 Initial Results . . . . . . . . . . . . . . . . . . . . . . . . 34

4 Results of Bering Sea Analysis $\quad 37$

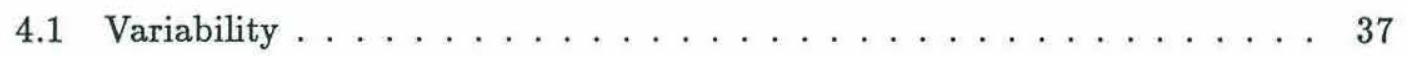

4.2 Discussion of Residual Profiles f . . . . . . . . . . . . . . 42

4.3 Further Tidal Analysis . . . . . . . . . . . . . . . . . . . . . . . 42

4.4 Application of a Gaussian Model to the Data Set . . . . . . . . . . . 53

4.4 .1 Methodology . . . . . . . . . . . . . . . 54

4.4 .2 Estimating the parameters . . . . . . . . . . 57

4.4 .3 Discussion of Results . . . . . . . . . . . . . . . 57 
4.5 The Circulation Puzzle . . . . . . . . . . . . . 60

5 Summary and Conclusions

71 


\section{List of Figures}

1-1 Bathymetry and geography of the Bering Sea. (From Sayles et al., 1968) 11

1-2 Satellite altimeter measurement relationships. (From Calman, 1987) . . 14

2-1 Tidal Station locations on the eastern Bering shelf . . . . . . . . 18

2-2 Locations of bottom pressure stations on the northeastern shelf from Mofjeld, 1986. . . . . . . . . . . . . . . . . 19

2-3 Contour map of bathymetry in the Bering Sea . . . . . . . . . . . . . . 21

2-4 Equirectangular projection of GEOSAT groundtracks in the Bering Sea region for the 17 -day repeat cycle. . . . . . . . . . . . . . 24

2-5 Seasonal subtrack coverage . . . . . . . . . . . . . . 26

2-6 Digitized map of descending repeat pass coverage . . . . . . . . . . . . . 28

2-7 Digitized map of ascending repeat pass coverage . . . . . . . . . . . 29

3-1 Residuals from original analysis containing bowed profiles . . . . . . . 35

4-1 Descending track sea surface height variability $\ldots \ldots \ldots \ldots$. . . . 38

4-2 Ascending track sea surface height variability . . . . . . . . . . 39

4-3 Depth-contoured sea surface variability from descending tracks . . . . 40

4-4 Example of Major Algorithm Stages . . . . . . . . . . . . . . . . . 43

$4-5$ Plot of d131 Residuals . . . . . . . . . . . . . . . . . . . . 44

4-6 Plot of d174 Residuals . . . . . . . . . . . . . . . . . . 45

4-7 Plot of Tidal amplitude along subtrack d045 . . . . . . . . . . . . 46

4-8 Comparison of modeled and observed tidal time series . . . . . . . . . 49

4-9 Definition Sketch of the Gaussian Model . . . . . . . . . . . . . 55 
4-10 Time series of Model Parameters and Surface Transport . . . . . . . . 61

4-11 Residual height profiles alongsubtrack a120 . . . . . . . . . . . 62

4-12 Time Series of height changes along subtracks a077, a120 and a163 . . . 64

4-13 Time series of height changes along subtracks a206 and a005 . . . 65

4-14 Components of the Circulation in the western Bering Sea . . . . . 67

4-15 Comparison of height change time series across the WBC and BSC . . 69 


\section{List of Tables}

4.1 Comparison of tidal variability with total sea surface height variability. . 47

4.2 RMS Variability of profiles before and after applying the ocean tide correction for tracks d131 and $\mathrm{d} 174 \ldots \ldots \ldots$. . . . . . . . . . 50

4.3 RMS Variability of profiles before and after applying tidal correction, for tracks a005 and a077 . . . . . . . . . . . . . 5 51

4.4 RMS Variability of profiles before and after applying tidal correction for

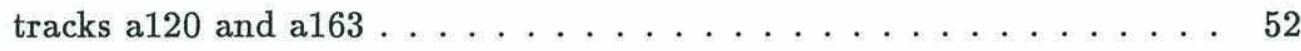

4.5 Gaussian Model Parameters . . . . . . . . . . . . . . . . . 58

4.6 Bering Slope Current Statistics . . . . . . . . . . . . 58

4.7 Height changes across ascending tracks, in meters . . . . . . . . . . . 63 


\section{Chapter 1}

\section{Introduction}

The Bering Sea, situated between the Alaskan coastline to the east and the Siberian coastline to the west, is divided in half in a northwest-to-southeast direction by the continental slope. The northeastern half is a broad continental shelf that continues through the Bering Strait, connecting the Bering Sea to the Arctic Ocean. The other half is dominated by an abyssal plain with depths in excess of $3500 \mathrm{~m}$. This sea and its strait provide the only means of exchange for water between the Arctic and $\mathrm{Pa}$ cific Oceans. An annual mean northward transport of $1.0 \mathrm{~Sv}$ (Kinder, memo to Kelly) flows through the strait, however, the source and path of the flow have not yet been established observationally. Although numerous direct current measurements over the southeastern shelf region of the sea allow for fairly detailed characterization of the flow in that area (Kinder and Schumacher, 1981), measurements for estimating transport and inferring significant flow paths across the entire shelf are inadequate, particularly near the Siberian Coast (Kinder et al., 1986). Consequently, current hypotheses of the circulation are based on synthesis of available observational evidence, laboratory experiment and numerical models. The purpose of this thesis is to examine the circulation in the Bering Sea, using data collected by the GEOSAT altimeter over the Bering Sea region from November 1986 to April 1988. The analysis will focus primarily on determining the variability of surface height from collinear profiles, in order to reveal any coherent patterns of circulation. 


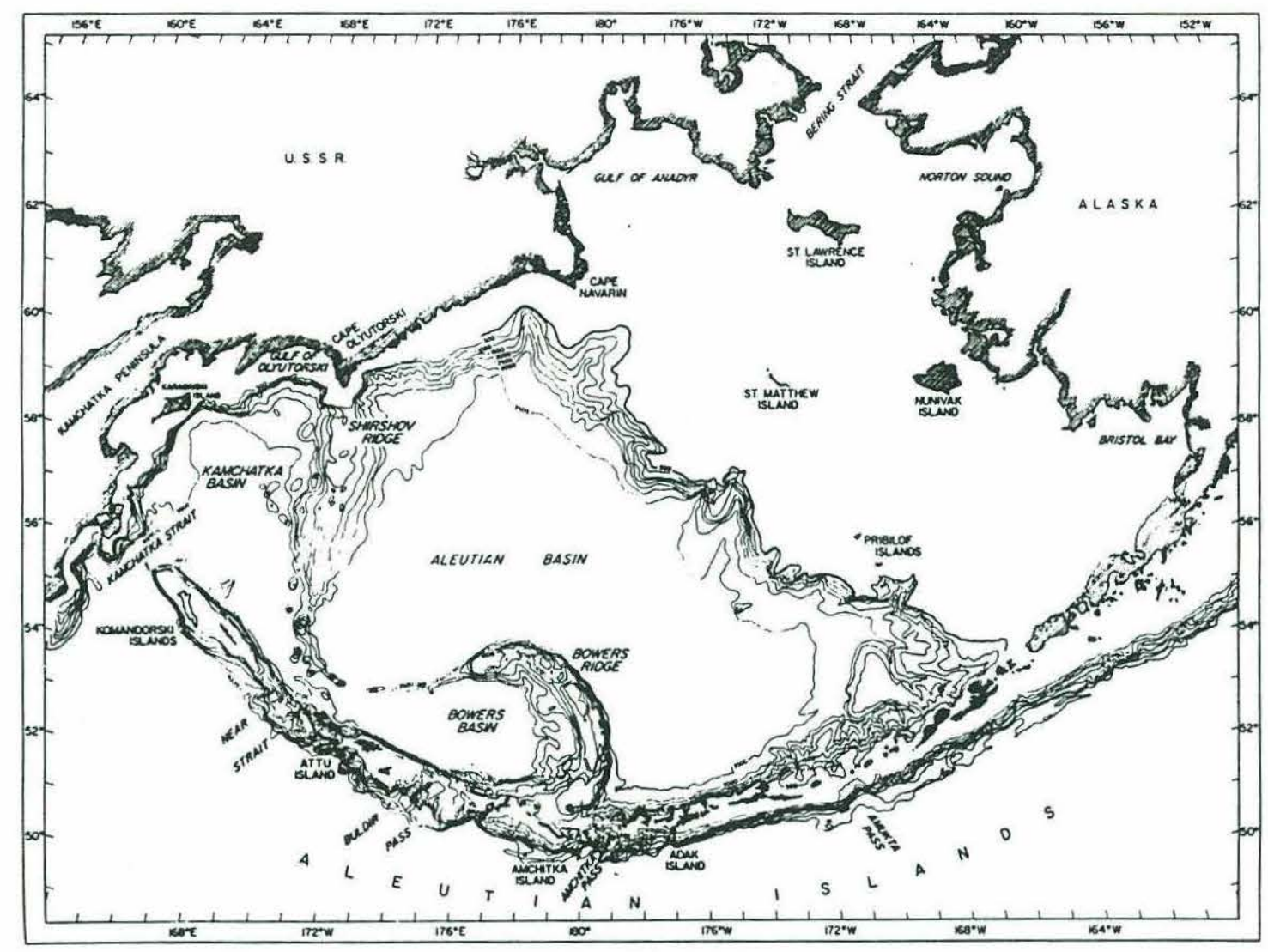

Figure 1-1: Bathymetry and geography of the Bering Sea. (From Sayles et al., 1968)

\subsection{Background Oceanography}

The possible sources and flow paths for the Bering Strait outflow are restricted by the various geographical and bathymetric features of the Bering Sea. Eighty-seven percent of the Bering Sea terrain is almost equally divided between a continental shelf region of less than $200 \mathrm{~m}$ depth and an abyssal region exceeding $3500 \mathrm{~m}$. The continental shelfbreak comprises the remaining 13 percent, extending approximately $1000 \mathrm{~km}$ from Unimak Pass in the southeast to Cape Navarin on the Siberian Coast. The Bering Strait, only $50 \mathrm{~m}$ deep and $85 \mathrm{~km}$ wide, connects the Bering Sea to the Arctic Ocean. The strait is bifurcated to the south by St. Lawrence Island, creating Anadyr Strait to the west and Shpanberg Strait to the east (Figure 1-1). River runoff and precipitation 
account for approximately two percent of the total transport through the strait, so the remaining source water for the outflow must come from off the shelf, or from the deep Aleutian basin. Insight from improved hydrographic measurements and some direct current measurements has narrowed the field of proposed paths to the two most feasible: a barotropic coastal buoyancy current along the Alaskan coast and a northward flow along the western boundary of the shelf (Overland and Roach, 1987). All hypotheses subscribing to this proposed pattern of flow agree that the western boundary current supplies the greater part of the Bering Strait outflow. Kinder et al. (1986) suggest that this greater flow, which crosses the shelfbreak at Cape Navarin, is due to a westward intensification of the Bering shelf current as it experiences a continuing decrease in depth flowing northward. They demonstrate this intensification through both a laboratory experiment and a numerical model which simulate the dynamics of drawing a flow across a shoaling bottom on a rotating earth. Their results are supported by Overland and Roach (1987), who examined the shelf circulation using a barotropic numerical model. Using independently calculated values of transport through the Bering Strait as references, they determined that the model produced a transport value closest to that actually observed when driven by a 0.4 meter sea level difference between the Pacific and Arctic Oceans. They then used this difference, which was consistent with hydrographic estimates, in an examination of circulation patterns on the Bering and Chukchi sea shelves. During this examination they calculated that flow through the western Anadyr Strait accounted for $72 \%$ of the Bering Strait outflow during the summer, in the absence of strong wind stresses. During the winter season, when stronger winds from the northeast dominated, flow through the Anadyr Strait almost equaled that through the Bering Strait, indicating that there was little or no net input from the Shpanberg Strait. Using an extensive series of long-term direct current measurements over the southeastern region of the shelf, Kinder and Schumacher (1981) calculated a transport of $0.08 \mathrm{~Sv}$ for the coastal buoyancy current, making it a source of less than ten percent of the Bering Strait outflow, again supporting the hypothesis that most of that outflow comes from the western boundary current. Most western boundary currents, such as the Gulf Stream and Kuroshio, exhibit root-mean-square (rms) sea 
height variability of $30-40 \mathrm{~cm}$ and peak-to-peak changes of $100 \mathrm{~cm}$ or more (Cheney et al., 1983), due to meandering, shedding of eddies and reversals or changes in speed. The signals they produce are easily measured by satellite altimeter and extracted from their data sets. Although the transport of the Bering Sea western boundary current is small relative to that of the Gulf Stream and Kuroshio, it appears to be the largest supplier of flow through the Bering Strait. It was anticipated that it would exhibit levels of variability large enough, relative to the surrounding environment, to be measured by the GEOSAT altimeter.

\subsection{Introduction to Satellite Altimetry}

The primary function of a satellite altimeter is the determination of the satellite's height above the sea surface. On the simplest level the altimeter consists of a transmitter that sends out sharp pulses toward the earth, a receiver to record the pulse after it is reflected from the surface and a clock to measure the round trip travel time of the pulse. Because the velocity of the radar pulse is known these times can be used to calculate the satellite's height above the surface. (For a detailed discussion of the operational mechanics and actual modifications of the basic theory, see Stewart (1985), section 14.2). As depicted in Figure 1-2, if $H_{o}$, the height of the satellite's orbit above a standard reference ellipsoid is also accurately known, the height of the sea surface referenced to the same ellipsoid is given by

$$
H_{s}(x, t)=H_{\circ}(x, t)-H_{a}(x, t)
$$

where $H_{a}(x, t)$ is the altimeter measurement of its height above the sea surface. If the ocean were at rest,the sea surface would vary only because of variations in gravity due to the irregular distribution of the earth's mass. This surface of constant geopotential, which varies worldwide by approximately $100 \mathrm{~m}$ (Born et al., 1982) is called the geoid ( $H_{g}$ in the figure.) Because the ocean is not at rest, however, there is a displacement $\eta$ of the sea surface relative to the geoid called the dynamic topography. According to Stewart (1985) causes of this departure include tides, winds, atmospheric pressure and 


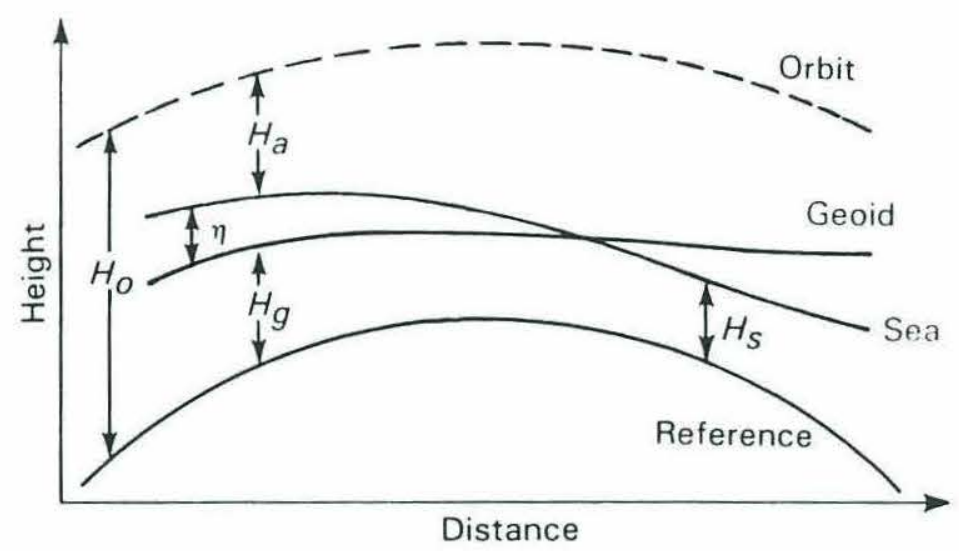

Figure 1-2: Satellite altimeter measurement relationships. (From Calman, 1987)

current systems with associated mesoscale features. Combining the definition of $\eta$,

$$
\eta(x, t)=H_{s}(x, t)-H_{g}(x)
$$

with (1.1) gives

$$
\eta(x, t)=H_{\circ}(x, t)-H_{a}(x, t)-H_{g}(x)
$$

Thus the accuracy with which sea surface topography can be mapped depends not only upon the accuracy of the direct altimeter measurement, but also upon the accuracy of the models used to predict the satellite's orbit and to calculate the geoid. The altimeter's ability to detect changes in this surface topography is useful, as surface slopes are often manifestations of surface geostrophic currents. To a good approximation surface currents are in equilibrium governed by the geostrophic balance,

$$
f v=-\frac{1}{\rho} \frac{\partial P}{\partial x}
$$

where $\mathrm{f}$ is the Coriolis parameter, $\mathrm{v}$ is velocity and $\mathrm{P}$ is pressure. Through this equation and the hydrostatic balance, given by

$$
g=-\frac{1}{\rho} \frac{\partial P}{\partial z}
$$


the geostrophic velocity can be calculated from the altimeter-measured sea surface topography by

$$
v_{s}=\frac{g}{f} \frac{\partial \eta}{\partial x}
$$




\section{Chapter 2}

\section{Data}

\subsection{GEOSAT Exact Repeat Mission}

The method employed in this study to examine variability in the Bering Sea utilizes collinear altimeter subtracks gathered during the GEOSAT Exact Repeat Mission (ERM) which officially became operational November 8, 1986. This mission provides repeated profiles of sea surface height along a groundtrack. Measurements are taken at a rate of 10.205 kilobits per second and are stored on board the spacecraft for approximately 12 hours (Jones et al., 1987), then transmitted to the Satellite Tracking Facility at the Johns Hopkins University Applied Physics Laboratory (JHU/APL). At the ground station there the data are preprocessed into Sensor Data Records (SDR's), then transmitted to the National Oceanic and Atmospheric Association (NOAA) processing facility where they are combined with ephemerides computed by NAG. Corrections are also added at this point to account for solid and fluid tides, and refraction due to the troposphere and ionosphere. The resulting form is distributed as a Geophysical Data Record (GDR). Each GDR provides the user with 34 channels of data approximately every second for a period of 24 hours or 14 to 15 revolutions. 


\subsection{Altimeter Corrections}

Optimum utilization of GEOSAT altimeter data for the study of mesoscale phenomena in the Bering Sea requires an overall measurement accuracy of approximately $10 \mathrm{~cm}$. All correction algorithms included in the processing must, therefore, be of comparable accuracy. As mentioned previously two immediate areas of concern are the accuracy of the geoid model and orbit predictions. Tapley et al. (1986) distinguished three other categories of error: (1) instrument corrections, (2) propagation medium corrections, and (3) effects of temporal variations in the ocean surface, such as tides. As explained in Campbell (1988), instrument errors can either be corrected or reduced by various techniques to acceptable levels and are not discussed further here (see Campbell [1988] or Stewart [1985] for more details).

\section{Tides}

Of the corrections included in the third category, Campbell's analysis demonstrated that the ocean tide correction had the greatest effect on total alongtrack variability. Standard corrections for the fluid or ocean tide supplied on the NODC data tapes are based on Schwiderski's (1980) global ocean model. The correction is interpolated along the subtrack at $7.3 \mathrm{~km}$ (one second) intervals from a one degree global grid of 11 tidal components. Although the depth limits on the model, $10 \mathrm{~m}$ to $7000 \mathrm{~m}$, seem to span shallow water regimes such as the Bering shelf, SEASAT experience has indicated that errors much larger than the estimated $10 \mathrm{~cm}$ error could occur near land and shallow water (Cheney et al., 1987). Recent work by Robinson and Dobson on the Eastern Iceland Polar front, a region with similarly low signal-to-noise ratio, indicated that the Schwiderski model is reliable to depths as shallow as $100 \mathrm{~m}$ (personal communication with A. Robinson, 1989), a marked improvement over the conventional $2000 \mathrm{~m}$ usually used as a depth limit (Flament, 1988; Kelly and Gille, 1989). While the Bering slope current and much of the proposed western boundary current occur in depths greater than this limit, a few areas of interest remain which do not. To investigate the variability in sea surface height due to tides, an examination of previous observations of tides over the Bering shelf was undertaken. For a three year 


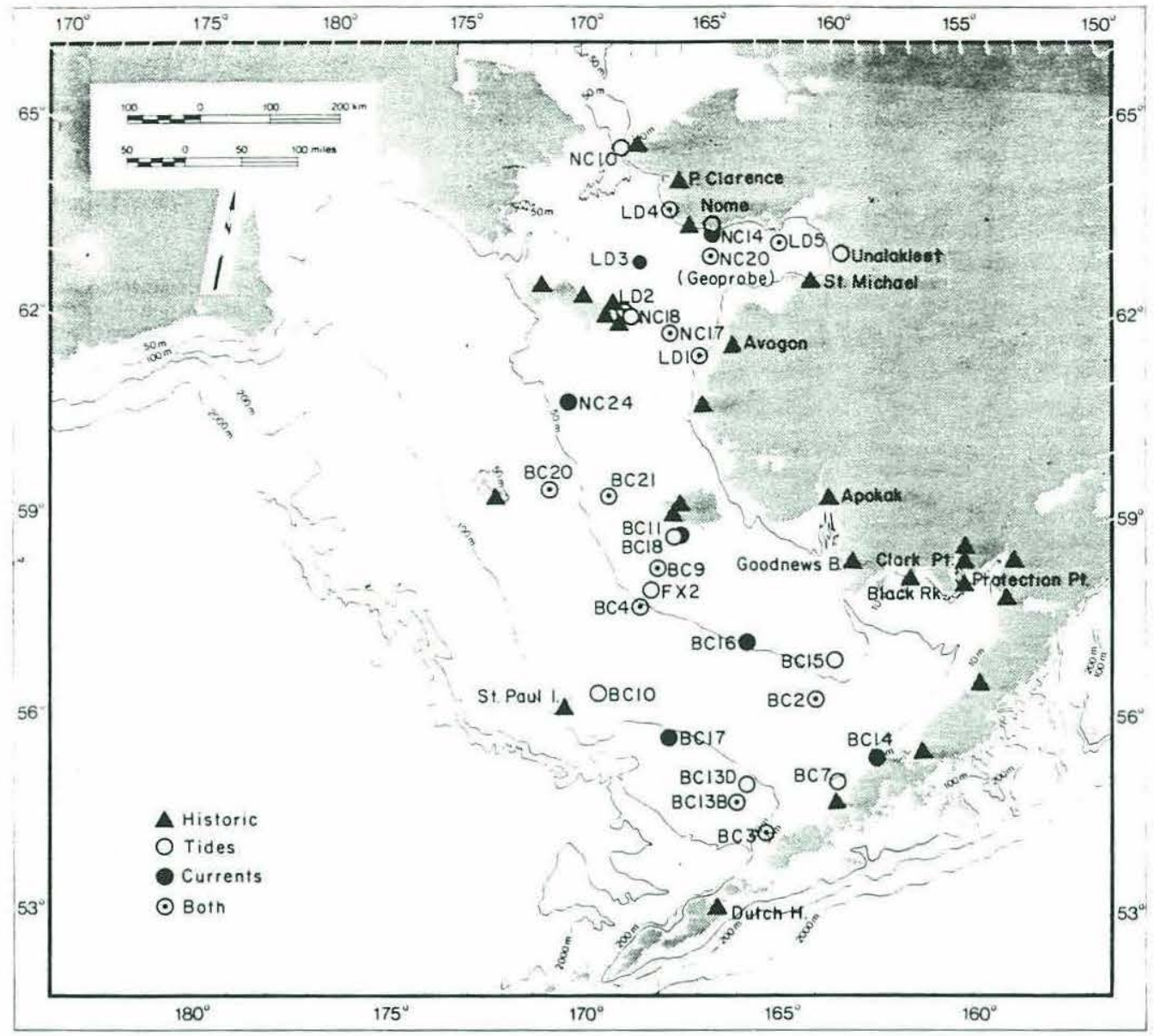

Figure 2-1: Locations of stations on the eastern Bering shelf, used in Pearson et al., 1981.

period, 1975-1978, observations were taken from a series of Aanderaa RCM-4 current meter moorings and Aanderaa TG2 and TG3 pressure gauges, positioned throughout the eastern Bering Sea shelf from the Alaskan Peninsula to the Bering Strait (Figure 21). Analysis of these observations (Pearson et al., 1981) revealed that the largest tides in the eastern Bering Sea occur on the inner southeastern shelf, particularly along the Alaskan Peninsula and interior Bristol Bay. Mofjeld (1986) extended the study of the tides to the edges of the northeastern sea shelf in his analysis of pressure gauge data, taken between November 1981 and August 1982 (Figure 2-2). This analysis indicated that diurnal tides dominated the outer reaches of the northeastern shelf with harmonic amplitudes ranging from $0.2 \mathrm{~cm}$ in the Bering and Anadyr Straits to $35 \mathrm{~cm}$ along the 


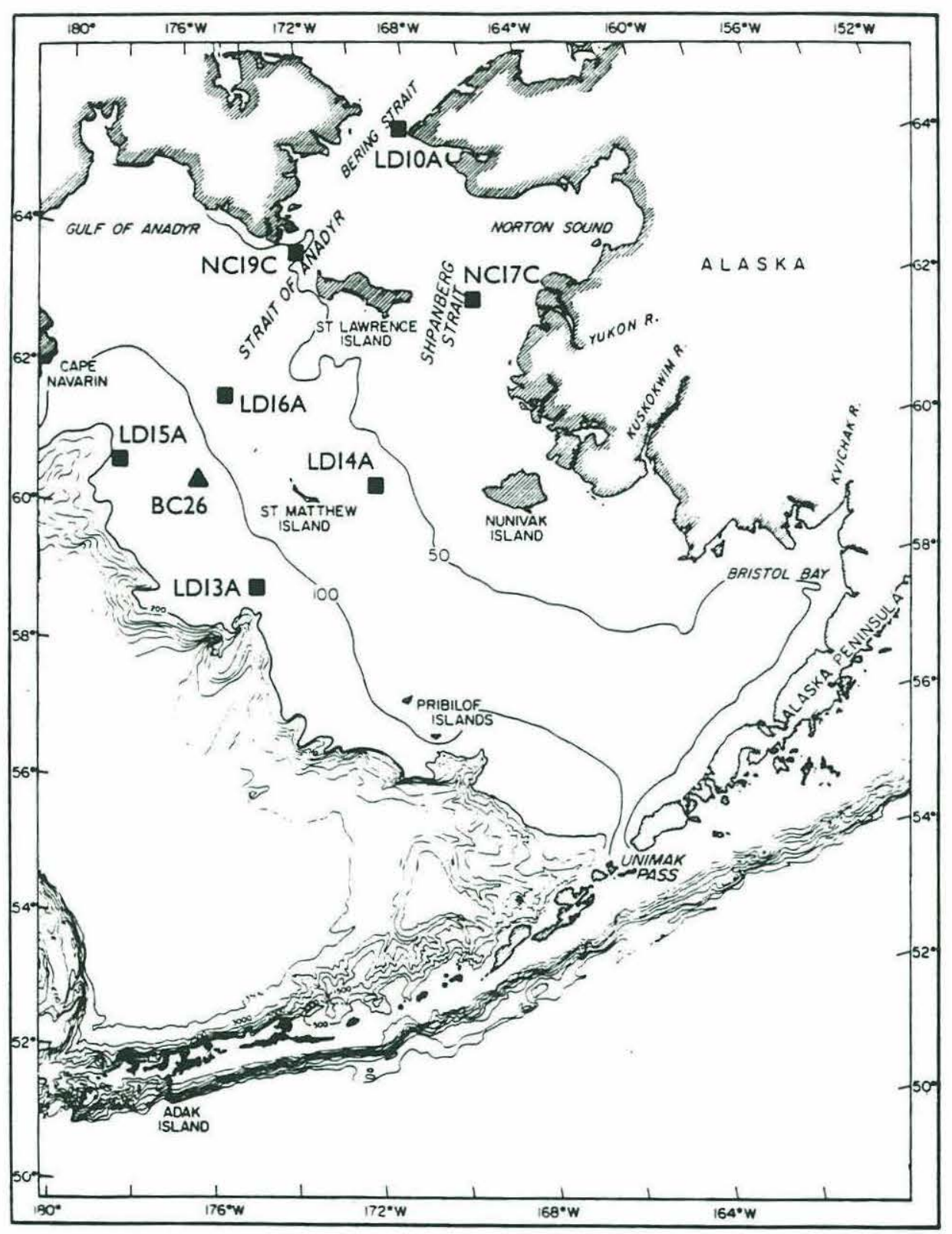

Figure 2-2: Locations of bottom pressure stations (squares) on the northeastern sea shelf from Mofjeld, (1986). The triangle indicates a current station on the outer shelf. 
shelfbreak, yet the phases remained relatively constant. Additionally, little variation in the tidal harmonic constants over seasonal time scales was observed. In both sets of observations, the lower order tidal constituents (diurnal and semi-diurnal) were found to comprise most of the tidal energy.

\section{Geoid}

As discussed previously, the accuracy with which sea surface topography can be determined depends not only upon the accuracy of the actual altimeter measurement, but also upon the resolution of the geoid. The GDR geoid is interpolated from one-degree height estimates computed by Rapp (1978). While this geoid can be used to initially reduce the variability of sea surface heights, it does so only to a $\pm 5 \mathrm{~m}$ range, too crude for most oceanographic applications. To circumvent the need for an accurate geoid a colllinear technique was chosen to examine the variability of the sea surface height with time, which allows for calculation of the variable geostrophic currents. With this technique one computes a mean sea surface, averaging over all the satellite repeat cycles, then calculates the difference between the surface topography during any one cycle and that mean surface. Since the contribution of both the geoid and its errors is independent of time, it is removed along with the mean surface. (See section 3.1 for more detail on collinear processing). Of more immediate concern is the possibility of residual geoid contamination. The areas most likely to induce geoid contamination are those of rapid geoid change which correspond to large bathymetric features. Figure 2-3 is a contour plot of the Bering Sea bathymetry. Contour intervals change from $1000 \mathrm{~m}$ southwest of the slope, to $25 \mathrm{~m}$ northeast of it. The most obvious region of large bathymetry gradients is the Aleutian Island trench; this trench contributes significantly to the total rms variability of the sea surface in that area. Fortunately this feature marks the southern boundary of the Bering Sea, which is not the region of primary interest for this study.

\section{GEOSAT Orbit}

Separation of actual sea surface height, $\eta$, from measured satellite height, $H_{a}$, requires an independent determination of the radial component of the satellite's or- 


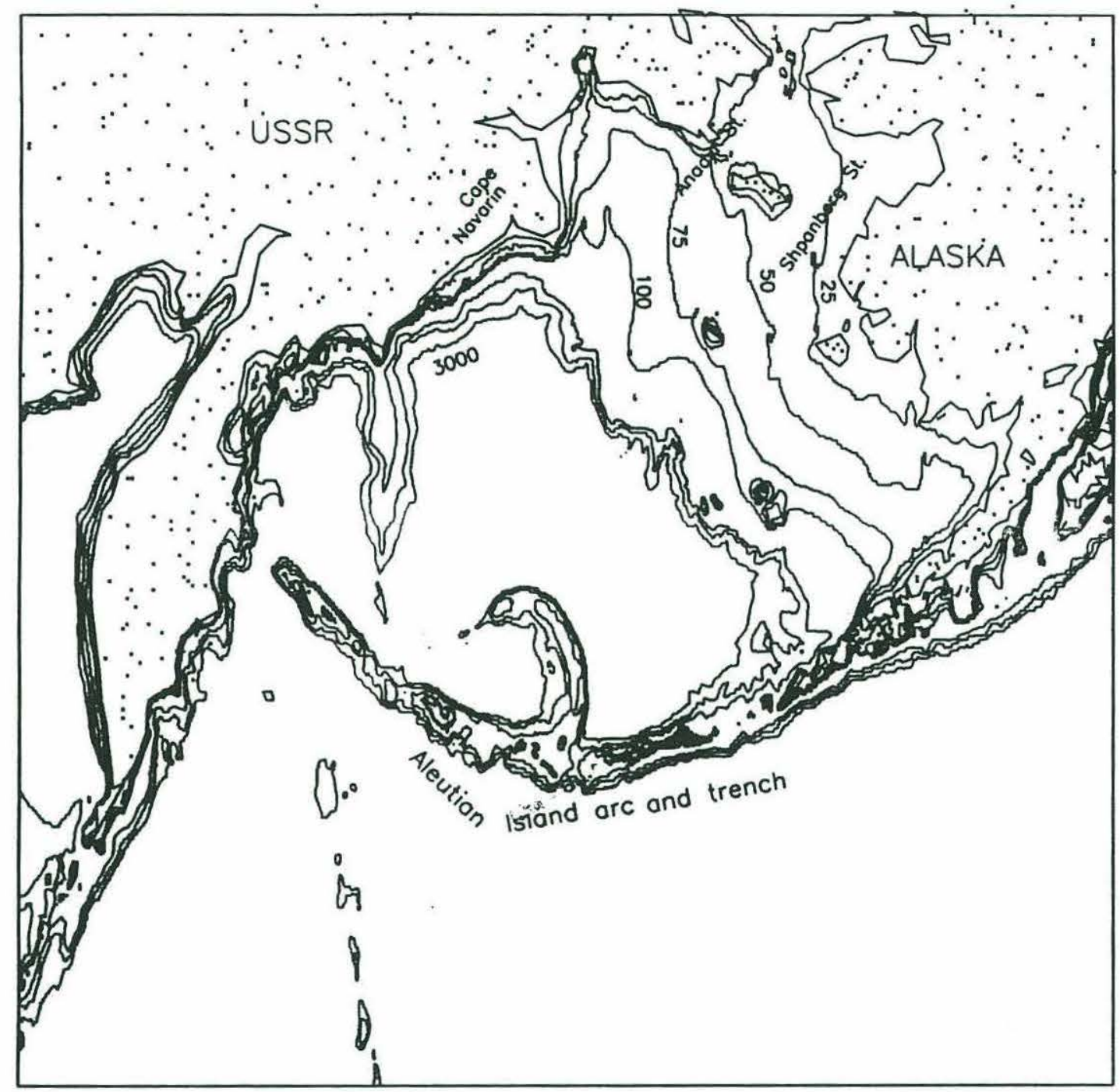

Figure 2-3: Contour map of bathymetry in the Bering Sea. Contour interval southwest of the slope is $1000 \mathrm{~m}$. Contours north of the slope are $25 \mathrm{~m}$ apart. Regions of large contour gradient, such as the Aleutian trench, may signal geoid contamination. 
bit. To satisfy this requirement for the GEOSAT ERM the orbit was calculated by the Navy Astronautics Group (NAG) from data collected at ground-based tracking stations. The accuracy of this calculated ephemeris depends on the accuracy and frequency with which the satellite's motion can be observed, the accuracy of the tracking station coordinates and a knowledge of the dynamic forces acting upon the satellite. During their evaluation of GEOSAT altimeter data in the tropical Pacific, Cheney et al. (1988) compared the operational Exact Repeat Mission (ERM) ephemeris calculated by NAG with a more accurate one computed by the Naval Surface Weapons Center (NSWC). They determined that the time-dependent error in altitude has an approximate magnitude of three meters at the orbital frequency. The amplitude, however, drops to $5 \mathrm{~cm}$ or less at twice the orbital frequency, revealing a long wavelength $(20,000 \mathrm{~km})$ character to the error, which allows it to be modeled successfully as a low-degree polynomial. Therefore, although uncertainties of three meters exist in the computed satellite altitudes, relative error between collinear passes can be eliminated by removing trends, whether linear or cubic, from the profiles, over arc lengths of several thousand kilometers. In this analysis, orbit error was modeled and removed as a parabola over an arc length of 30 degrees or approximately $4300 \mathrm{~km}$.

\section{Atmospheric Effects}

Range errors due to the atmosphere are caused by the modification of the atmosphere's index of refraction. In the trophosphere this change is caused by the presence of water vapor and other gases, and in the ionosphere, by the presence of free electrons. In both cases, the change in refractive index alters the electromagnetic propagation speed, thus changing the elapsed time between transmission and reception of the altimeter radar pulse, and biasing the inferred distance to surface. Of the three corrections for the altimeter, wet and dry tropospheric and ionospheric, the wet tropospheric is the most unreliable. Although its magnitude is not as great as that of the dry atmospheric correction, its length scales can match those of mesoscale ocean phenomena, thereby degrading the accuracy of the sea surface height calculation. All the errors mentioned above occur on various length scales and are of a wide range of magnitudes. Very 
large-scale errors and signals are removed in the orbit correction procedure explained in chapter 3 , thus only mesoscale errors are critical to the analysis.

\subsection{Terminology}

In each 17-day period GEOSAT overflies the Bering Sea region defined as a rectangular box bounded at $40^{\circ} \mathrm{N}$ and $70^{\circ} \mathrm{N}$ latitude and $152^{\circ} \mathrm{W}$ and $208^{\circ} \mathrm{W}$ longitude, making measurements along 70 subtracks. The subtracks occur in two groupings: the northwest-southeast trending tracks are called ascending passes, and the northeastsouthwest trending ones are descending passes. The entire 17-day set of ascending and descending passes fills out the skewed checkerboard pattern depicted in Figure 2-4. After 17 days, the passes repeat, tracing over previous subtracks. For this analysis orbits were processed for the time period of November 1986 to June 1988, providing 35 repeat cycles. Consequently, each subtrack in this study represents an ensemble of as many as 35 collinear passes separated in time by 17 days. Each pass is labeled according to the orbit subtrack it traces prefixed by the number of the repeat cycle it belongs to, beginning with zero. For example, c001.d045 is the second descending pass for orbit 45.

\subsection{Data Characteristics}

This set of observations provides a time series of sea surface height changes with an along-track resolution of $7.3 \mathrm{~km}$ and a precison of $3-4 \mathrm{~cm}$ (Cheney et al., 1988). The $1 \frac{1}{2}$-year sampling period allows for observation of long-term phenomena, however the 17-day repeat cycle limits the phenomena to those with periods of more than half a month. As the focus of this analysis is the detection of the major current paths in the sea, this limitation is not critical. Additionally, the cross-track grid described by the ground tracks, approximately $70 \mathrm{~km}$ apart in the Bering Sea region, is adequate for detecting features with spatial scales on the order of $100 \mathrm{~km}$ or more. From a spatial

perspective, then, the resolution of the GEOSAT altimeter is well-suited to detecting the patterns of mesoscale activity. One other characteristic feature of the data in 


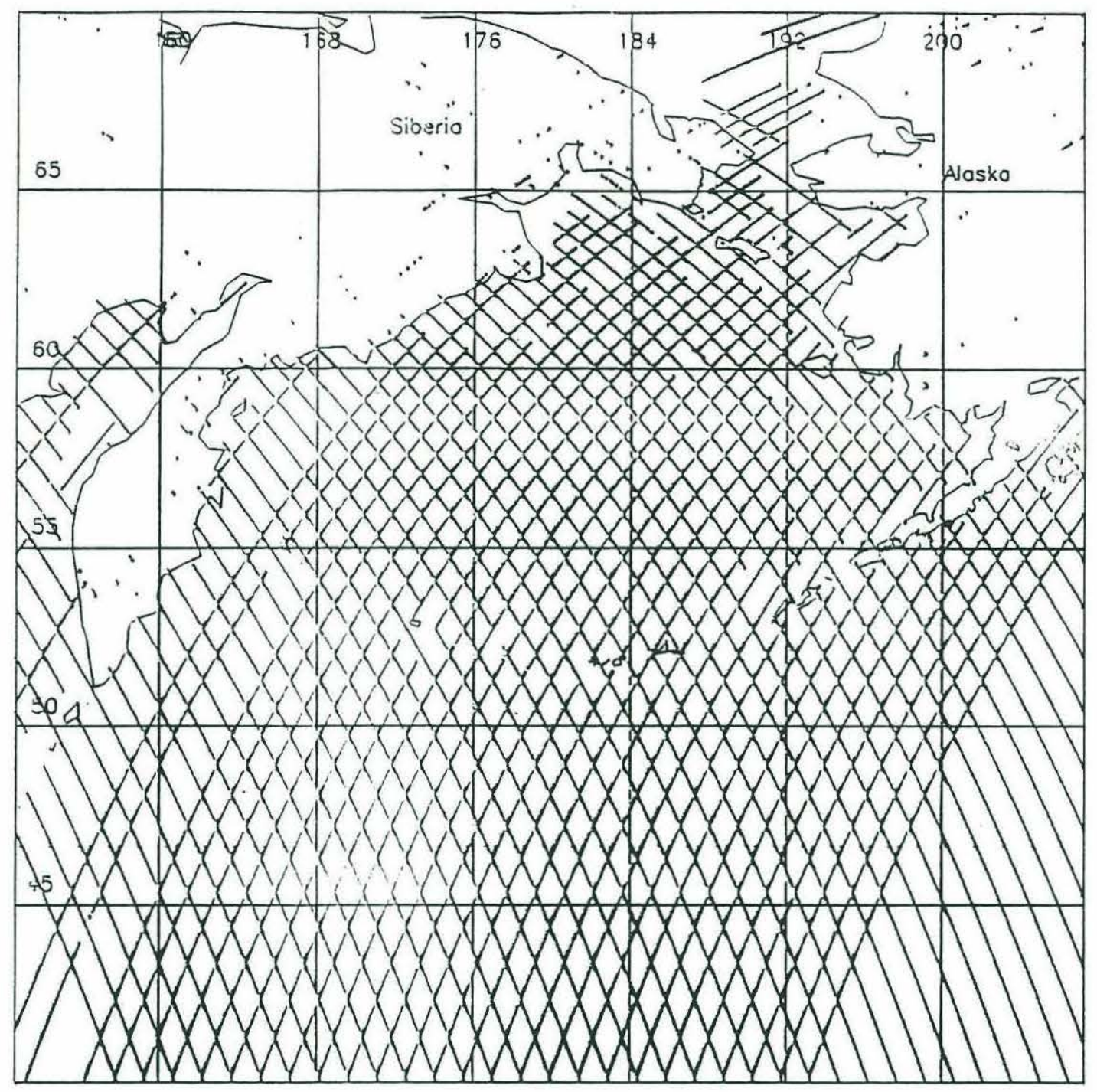

Figure 2-4: Equirectangular projection of GEOSAT groundtracks in the Bering Sea region for the 17-day repeat cycle. 
the Bering Sea region is the seasonal variation in coverage caused by ice formation. The ice pack dominates the sea from January to May, although it generally begins its seasonal formation in the northern reaches of the sea in November and by March has extended to its southern limit at $60^{\circ} \mathrm{N}$. Melting usually begins in late March, at a faster rate than formation, so that by July the Bering Sea is ice-free and remains that way through October (Niebauer, 1981). As with most processes in the region, however, the advance and retreat of the ice is variable, depending largely on surface winds, sea and air temperature and broad-scale meteorological events. To the altimeter ice-covered areas present a more irregular and varying surface topography than open ocean areas. When the change in the range or distance to the surface exceeds a certain deviation from pulse-to-pulse along the satellite path, range measurements are no longer taken (Zwally et al., 1981) and gaps in coverage ensue. Figure 2-5 demonstrates the change in subtrack coverage over the Bering Sea at different times in the year. The map in Figure 2-5(a) corresponds to the coverage of cycle 5, from January 31, 1987 to February 15,1987 , when the ice pack dominates the sea. During this time there is little coverage in the northern half of the sea. Even below the ice limit there is sparse coverage; what is available is provided mostly by ascending (northwest to southeast tending) passes. In Figure 2-5(b) the spring melt has begun. Because the melt begins on the southern side the southern region becomes ice-free relatively quickly and subtrack coverage improves. The northern area, however, remains ice-covered. Figure 2-5(c) depicts full summertime subtrack coverage, when the area is entirely ice-free. By fall, (Figure 2-5(d)) the ice-pack formation has begun again in the northern reaches, causing limited satellite coverage there; southern areas of the ocean are still ice-free however, and are well-represented in the coverage. Results of this seasonal variation in coverage are demonstrated in Figure 2-6 and Figure 2-7, composite displays of ascending and descending subtrack coverage for the entire $1 \frac{1}{2}$ year sampling period. At each location along a groundtrack, the number of repeat cycles that were available for processing at that point was calculated and assigned a grey-shade representing a scale from 0-35 cycles. These grey-shade values were processed into an image using the Satellite Data Processing System developed at Woods Hole (Caruso and Dunn, 1989). The absence 


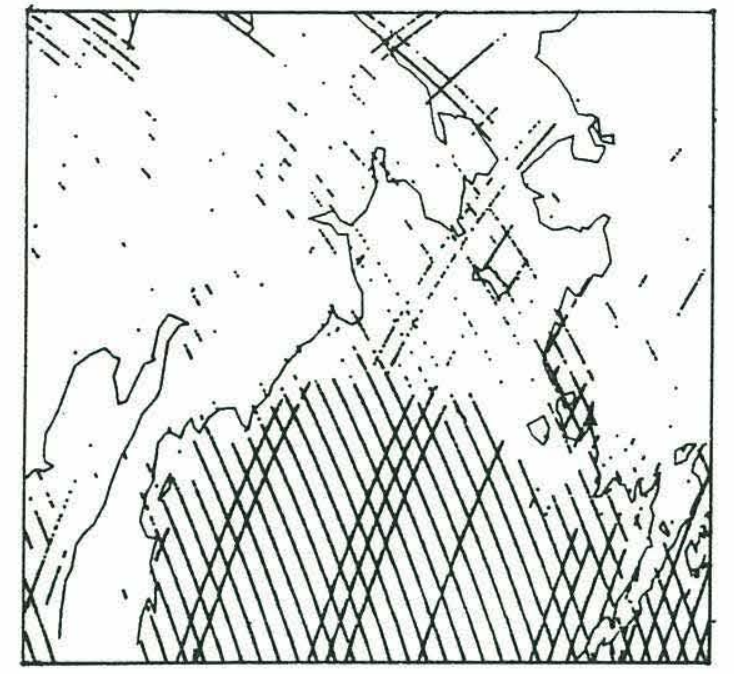

(a)

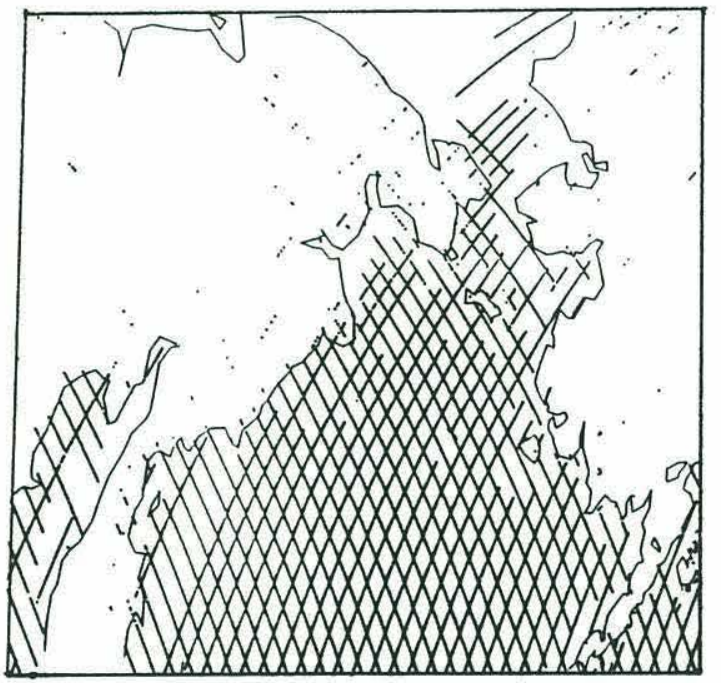

(c)

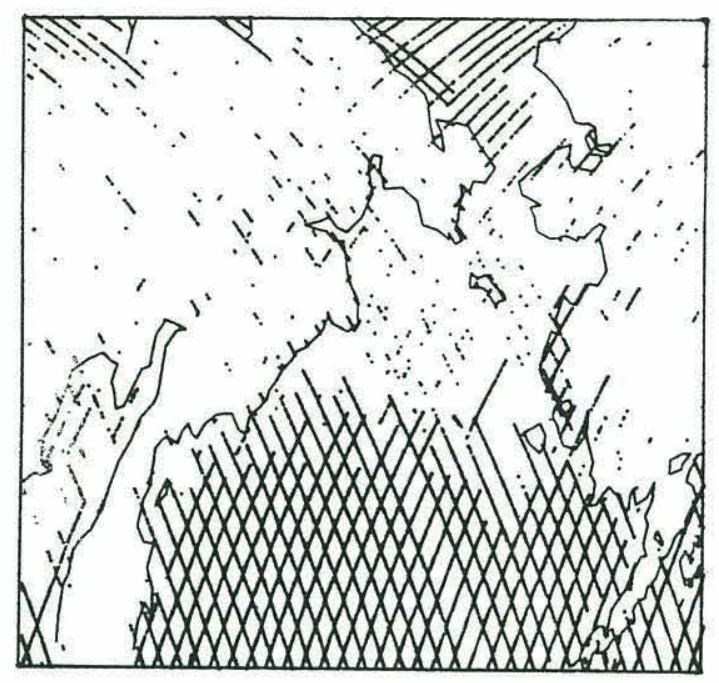

(b)

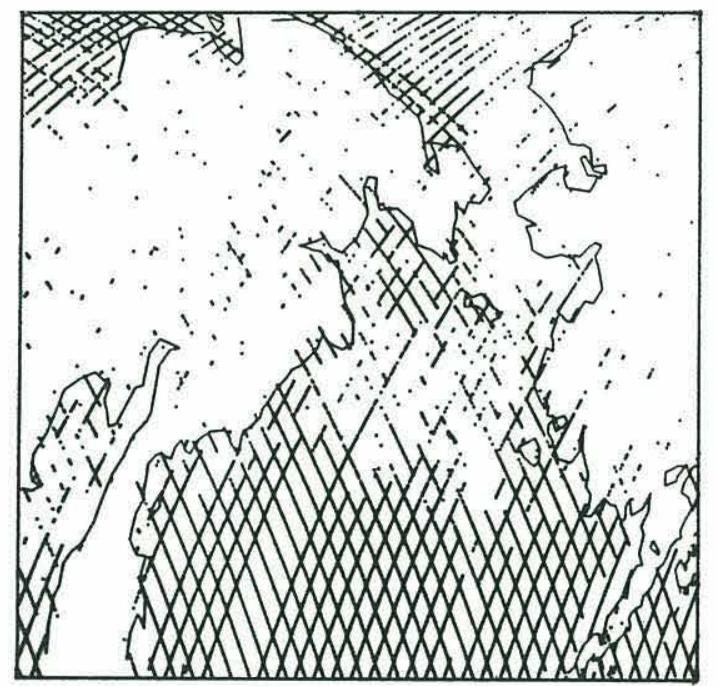

(d)

Figure 2-5: Seasonal subtrack coverage. (a) coverage from $31 \mathrm{Jan} 87$ to 15 Feb 87 ; (b) coverage from 9 Apr 87 to 25 Apr 87; (c) coverage from 16 Jun 87 to 2 Jul 87; (d) coverage from 26 Sep 87 to 13 Oct 87 . 
of subtrack coverage in the northern area of the sea during the better half of the year is evidenced by the low number of collinear passes seen in this figure. The region of greatest coverage or highest count, on the other hand, is the southern area below the ice limit. Because of this seasonal variation in coverage, results are biased toward those periods when there was little ice-cover in the sea. 


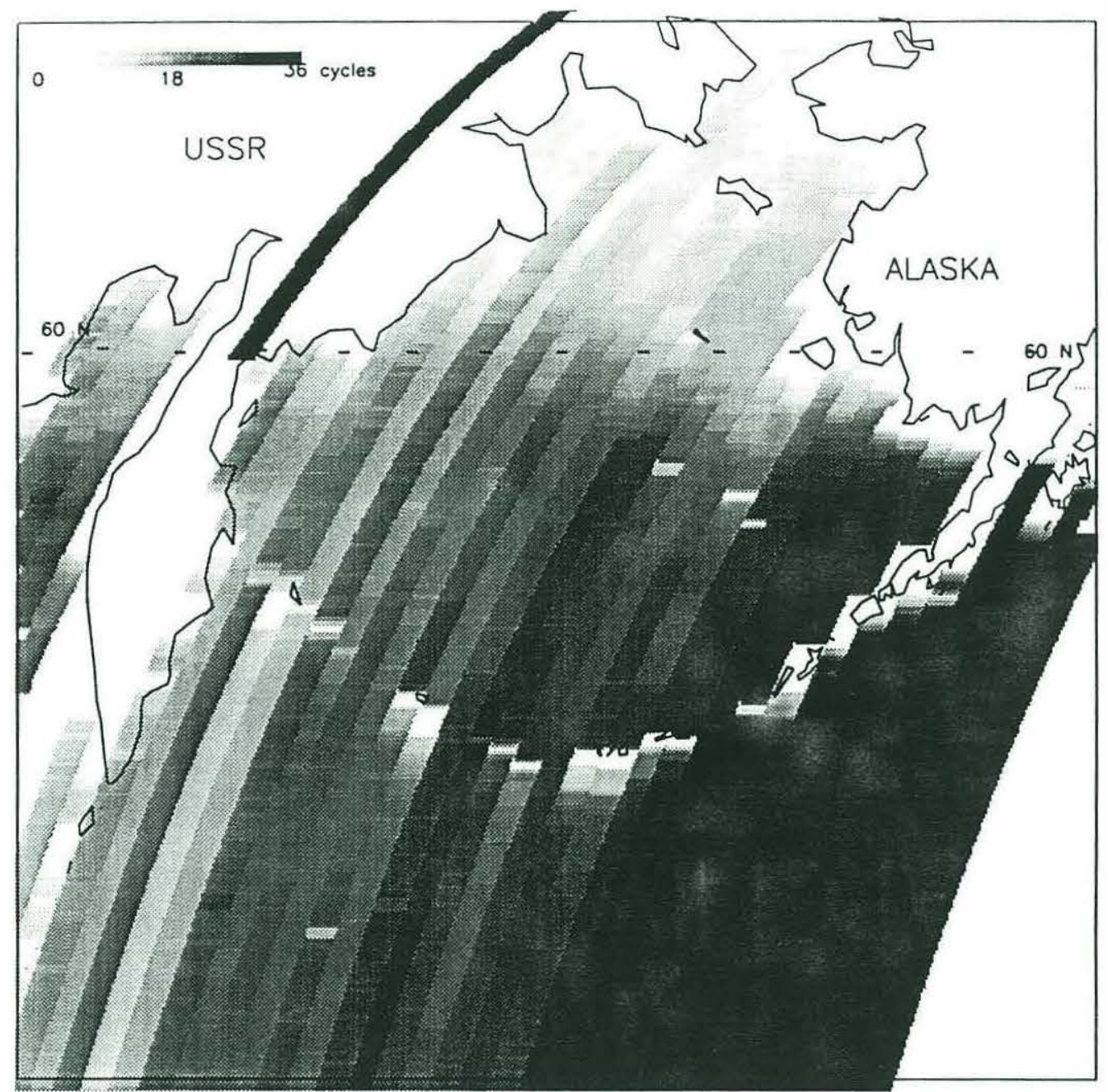

Figure 2-6: Grey-scaled composite mapping of repeat passes available for processing along descending groundtracks. Darker colors indicate a lower number of passes. 


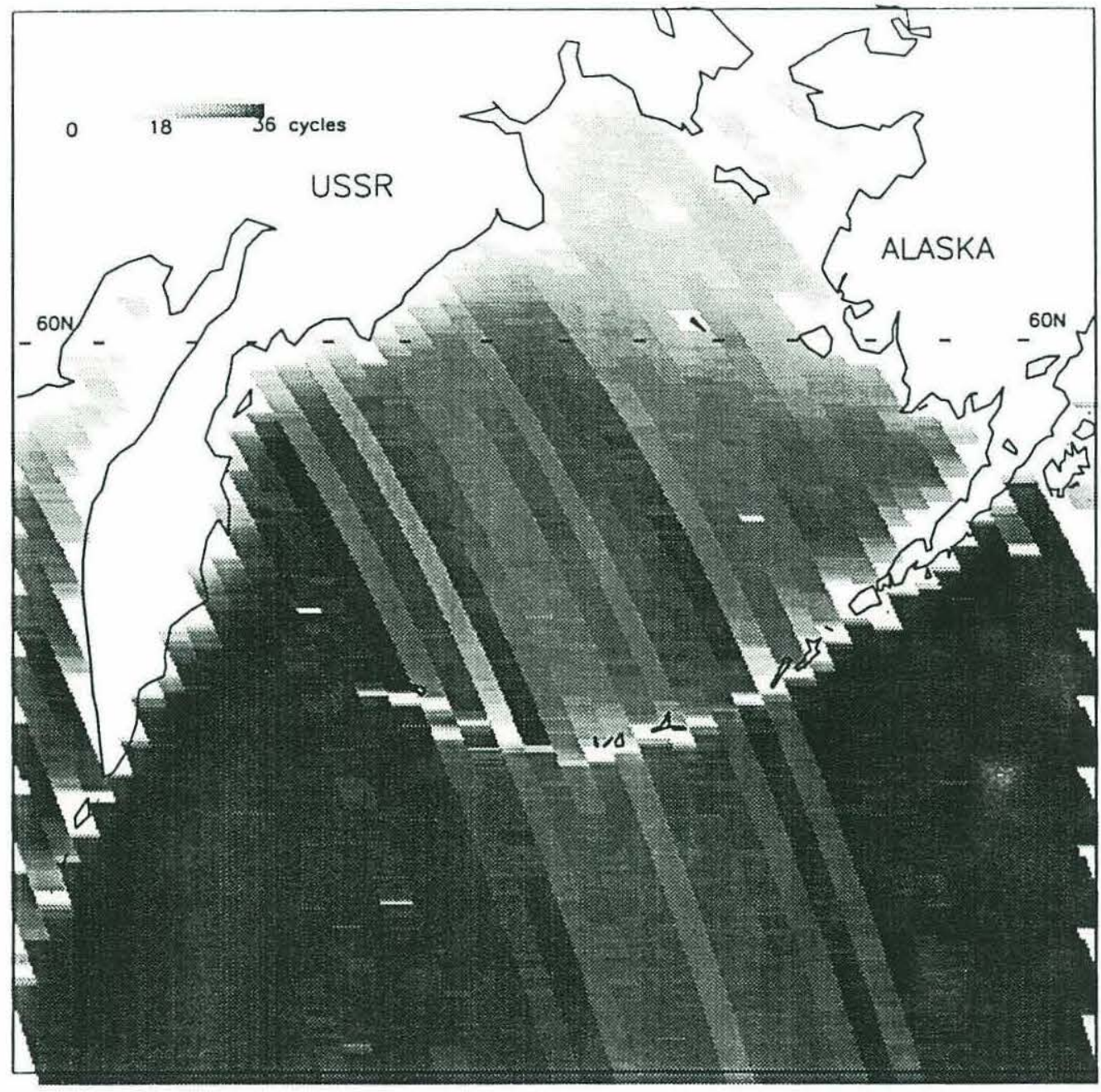

Figure 2-7: Grey-scaled composite mapping of repeat passes available for processing along the ascending groundtracks. 


\section{Chapter 3}

\section{Method of Analysis}

\subsection{Collinear Processing Techniques}

Ocean current systems with length scales greater than about $50 \mathrm{~km}$ and time scales longer than one day are maintained by horizontal pressure gradients, and manifested at the surface as changes in height relative to the geoid, a level of constant geopotential. While satellite altimeters are precise enough to detect these surface slopes, the extraction of the absolute dynamic topography still depends upon a knowledge of the geoid on comparable length scales. With the exception of a few geoids, such as the Marsh and Chang (1978) gravimetric geoid for the Northwest Atlantic, such knowledge is unavailable. Altimetric studies, therefore, have focused on estimating the temporal variability of sea surface heights, using either a collinear or crossover technique (Thompson et al., 1983; Cheney et al., 1983; Tai and Fu, 1986.) A collinear technique was chosen for this analysis because it is effective for investigating smaller mesoscale features, requires less processing time and uses a simpler algorithm. The total dynamic topography along a repeat cycle is the sum of a time varying-component $\eta^{\prime}(x, t)$ and the mean dynamic topography, $\langle\eta(x)\rangle$, or,

$$
\eta(x, t)=\eta^{\prime}(x, t)+<\eta(x)>
$$


From the earlier discussion of the altimeter measurement system, however, the total dynamic topography is also given by

$$
\eta(x, t)=H_{s}(x, t)-H_{g}(x)
$$

where $H_{s}(x, t)$ is the altimeter-measured sea surface height profile and $H_{g}(x)$ is the geoid height. Averaging an ensemble of repeat cycles in time along a given subtrack gives a mean height profile $\left\langle H_{s}(x)\right\rangle$ such that

$$
<H_{s}(x)>=\left\langle\eta(x)>+H_{g}(x)\right.
$$

The mean profile is the combination of the mean of the dynamic topography along the track, and the geoid, which is assumed to be the same for all passes along a given subtrack. Combining and simplifying the above three equations produces an expression for the variable dynamic topography which eliminates the need for explicit knowledge of the geoid:

$$
\eta^{\prime}(x, t)=H_{s}(x, t)-<H_{s}(x)>
$$

In other words, residual profiles of dynamic topography are produced by subtracting the mean sea surface height profile for a given subtrack from the height profile of each individual repeat pass. There are two major disadvantages to using a collinear analysis. The first is that removing the mean sea surface height removes the mean dynamic topography also, so that collinear analyses are useful for studying only the height field variability. The second disadvantage is the possibility of residual geoid contamination. In practice, successive GEOSAT repeat tracks do not exactly coincide, but fall within a one kilometer band in the crosstrack direction. Significant crosstrack geoid gradients induce a time-dependency in the $H_{g}$ term in equation (3.2),

$$
H_{g}=\left\langle H_{g}>+H_{g}^{\prime}\right.
$$

The residual profiles, $\eta^{\prime}(x, t)$, then contain an extra term, $H_{g}^{\prime}$, which may be mistaken for oceanographic features. This problem provided the motivation for the weighted regression scheme used in this analysis and is discussed in more detail in the next section. Another problem is the possibility of temporal aliasing of tides. GEOSAT repeats a 
given subtrack every 17.05 days, thus providing "pictures" of the ocean surface at that time interval. Non-random signals such as tides can be aliased into the mean sea surface height profile and subsequently alter the residual profiles. Campbell (1988) computed the tidal aliasing periods for the major tidal constituents. The largest in amplitude and most likely to be aliased into the mean was the S2 component. Fortunately the S2 component in the Bering Sea has anomalously low amplitudes (Mofjeld, 1986), and the aliasing problem is neglible here.

\subsection{Collinear Processing Algorithm}

The collinear processing algorithm used in this analysis was developed by P. Flament and modified by Z. Sirkes and M. Caruso of the Woods Hole Oceanographic Institution. The sequence of steps in the algorithm is described here in more detail:

\section{Extraction and Grouping of Data}

Thirty-five repeat cycles of data, (November 1986 to June 1988), were extracted from the GDR tapes. Only those subtracks which crossed the bounds defining the Bering Sea region (see section 2.2) were extracted. The segments extracted had arc lengths of approximately 30 degrees, or $4300 \mathrm{~km}$ alongtrack. The data, originally organized by repeat cycle, were then regrouped by subtrack for easy processing of collinear tracks.

2. Preprocessing of Ten Per Second $\left(10 s^{-1}\right)$ Data

Unlike SEASAT data, GEOSAT data are available at rates of both ten-per-second $\left(10 s^{-1}\right)$ and one-per-second (1-s) averages (Cheney et al., 1987). To prevent data spikes from being averaged into the 1 -s data the $10 \mathrm{~s}^{-1}$ values were corrected and edited before being averaged. Each $10 \mathrm{~s}^{-1}$ datum was corrected for tides, water vapor, tropospheric and ionospheric delays and surface pressure, using the correction factors provided for the corresponding 1-s average on the GDR tapes. The $10 \mathrm{~s}^{-1}$ values were then edited to eliminate spikes and anomalous values using a linear least squares fit over seven consecutive points. For this first fit, points 
which deviated from the fit by more than twice the rms error were eliminated, the filter was moved ahead one point, and the process repeated through the end of the data set.

\section{Computation and Regridding of 1-s Averages}

Once the $10 \mathrm{~s}^{-1}$ values were edited, new 1-s averages were computed from the five corrected values on either side of a new latitude grid. A common latitude grid was used for the averaging of collinear tracks. Once interpolated to the common latitude grid, the 1-s averages were filtered. This time a second-order polynomial was fit to seven consecutive points. If the difference between a point and the mean of the fit at that point exceeded $2 \mathrm{~m}$ the point was eliminated, the filter shifted over a point and repeated through the end of the data set. The entire fit procedure was repeated a second time with a new error allowance of $0.25 \mathrm{~m}$.

4. Modelling and Removal of Orbit Error

Once the data were filtered and regridded, the orbit error was removed using a two-step procedure. The first step gave an estimate of the data variance at each point along a subtrack. A mean sea surface profile was estimated as the time average of the available collinear profiles, and subtracted from each individual profile giving:

$$
h\left(x_{i}, t\right)-<h(x)>=\hat{y}\left(x_{i}, t\right)
$$

where $h\left(x_{i}, t\right)$ is the edited sea surface height profile, $\langle h(x)\rangle$ is the estimated mean height profile and $\hat{y}\left(x_{i}, t\right)$ is the residual profile. A parabola, $a(t) x_{i}^{2}+$ $b(t) x_{i}+c(t)$, was least-squares fit to this first residual profile, and an estimate of the variance, $\sigma^{2}$, was computed by

$$
\sigma^{2}=\frac{1}{N} \sum_{t=0}^{N}\left\{\hat{y}\left(x_{i}, t\right)-\left[a(t) x_{i}^{2}+b(t) x_{i}+c(t)\right]\right\}^{2}
$$

where $\mathrm{N}$ is the number of repeat cycles used to estimate the mean profile. A second regression was performed, this time weighted by the inverse of the variance, to determine the orbit error coefficients. Weighting by the inverse of the variance 
decreased the contribution of areas with geoid contamination. The coefficients were determined by minimizing the error, $\epsilon^{2}$, given by

$$
\epsilon^{2}=\sum_{x_{i}}^{n}\left\{\hat{y}\left(x_{i}, t\right)-\left[a(t) x_{i}^{2}+b(t) x_{i}+c(t)\right]\right\}^{2} \frac{1}{\sigma^{2}\left(x_{i}\right)} .
$$

The parabolic orbit error was subtracted from each original individual height profile to produce the final set of detrended profiles, $h^{\prime}$,:

$$
h\left(x_{i}, t\right)-\left[a(t) x_{i}^{2}+b(t) x_{i}+c(t)\right]=h^{\prime}\left(x_{i}, t\right)
$$

\section{Removal of Mean Sea Surface}

After the orbit error was removed, all cycles were averaged obtain the mean profile along each subtrack. This mean profile was then subtracted from each individual profile to eliminate the geoid.

\section{Calculation of rms Variability}

The variability of the surface along each subtrack was computed from the final set of residual height profiles. These values were then color coded on a scale of 0 - $0.4 \mathrm{~m}$ and processed into a digitized map. These maps and pertinent residual height profiles are presented and discussed in chapter 4.

\subsection{Initial Results}

The inclusion of the second weighted regression (1.8) was more effective in removing orbit erors than the original method which did not use the data variance to determine the parabola. The first set of residual profiles, produced without the weighted regression contained profiles with a suspicious curvature, similar to that seen in the middle group of profiles in Figure 3-1. Several suspected causes for the bowing were examined. The first possible cause was the length of the profile. Because the orbit error was modeled as a parabola over a 30-degree arc instead of as a tilt and bias, extreme curvature was induced in short data files forced to fit the parabolic model. Therefore, profiles shorter than approximately five degrees were subsequently discarded. While this adjustment removed the most extreme cases of bowing, there were longer profiles 


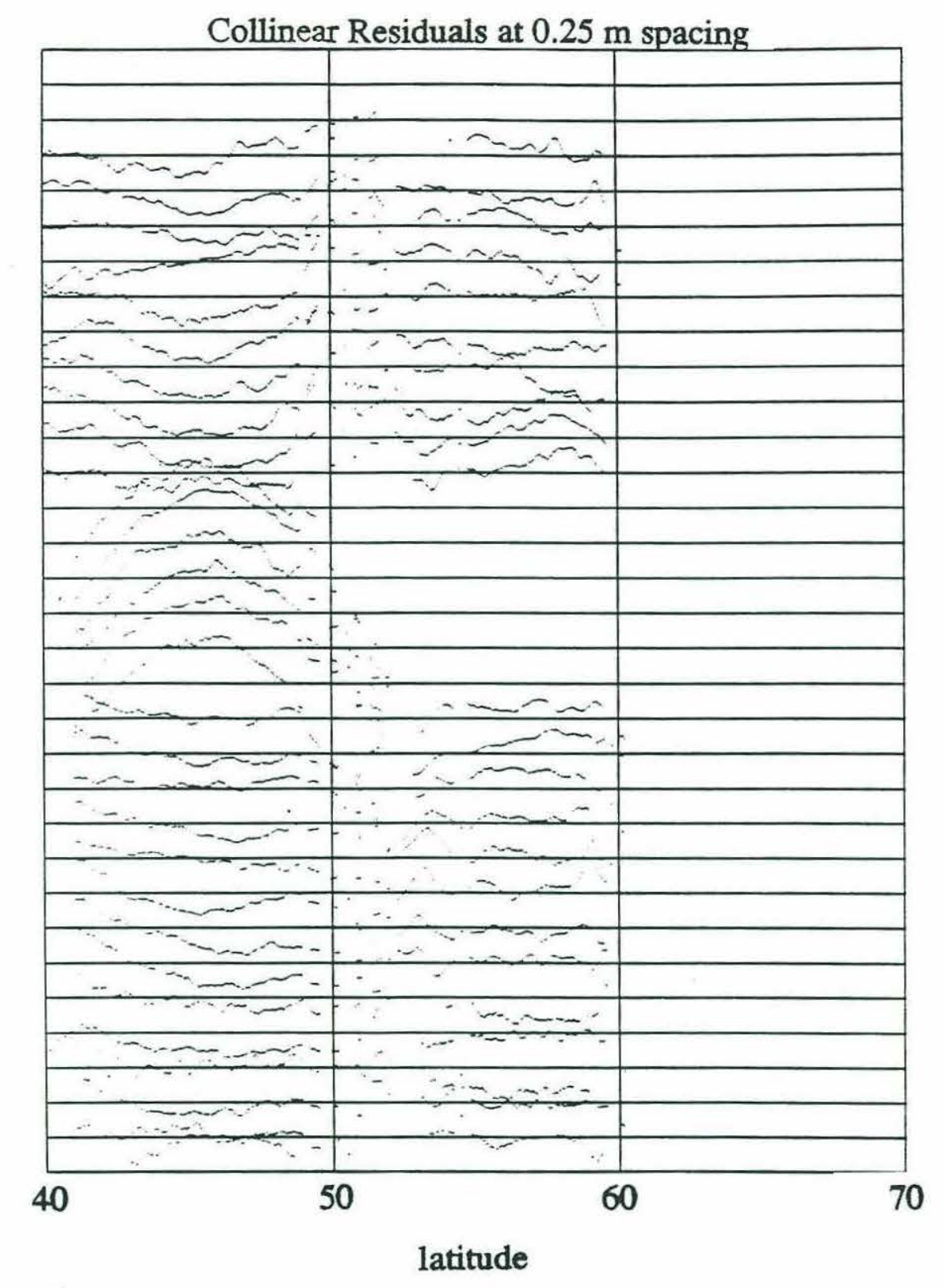

Figure 3-1: Residuals from original analysis of repeat cycles along track a006.The bowed profiles are caused by steep longitudinal geoid gradients. 
with bowing that was less severe. The profiles were then reprocessed using the weighted regression technique. The curvature disappeared, suggesting that geoid contamination was responsible. The slight non-collinearity between passes and the large cross-track geoid gradients over the trenches produced large geoid variability. A simple leastsquares fit to these large signals produced a parabola with a higher-than-usual degree of curvature over the length of the track. Subtracting this parabola from the original profiles induced a corresponding distortion in the height residuals. The weighted regression essentially ignored areas of unusually high variability in computing the parabola, resulting in better orbit error estimates. 


\section{Chapter 4}

\section{Results of Bering Sea Analysis}

\subsection{Variability}

Figures 4-1 and 4-2 are digitized maps of sea surface variability from descending and ascending subtracks, respectively. The stripes in each map represent temporal sea surface height variability along each groundtrack. In the center of each map, just north of the Aleutian Island arc is the Bering Sea basin, with depths greater than $3000 \mathrm{~m}$. Variability over the basin is low, usually less than $0.1 \mathrm{~m}$. In Figure 4-1, however, a region of higher variability extends into the basin. When depth contours are superimposed on this map as in Figure 4-3, this region coincides with the curve of a small "arm" of comparatively shallow water reaching out from the Aleutian islands. While it is possible that this "arm" produced a trapped oceanographic response, it is considered more likely that the variability is due to geoid contamination and not a permanent mesoscale feature. Further north is another path of higher variability extending from the tip of the Alaskan Peninsula to a point just south of Cape Navarin. The locations of the darker pixels along each track coincide closely with the proposed position of the Bering slope current. The areas of high variability in the ascending map are found along the southeastern coastal reaches and in the Gulf of Anadyr. Because these regions are close to land masses, one would normally suspect the higher variability to be caused by failure of the altimeter to readjust immediately after the transition from land to water and vice-versa. However, close examination of the western coast south of Cape 


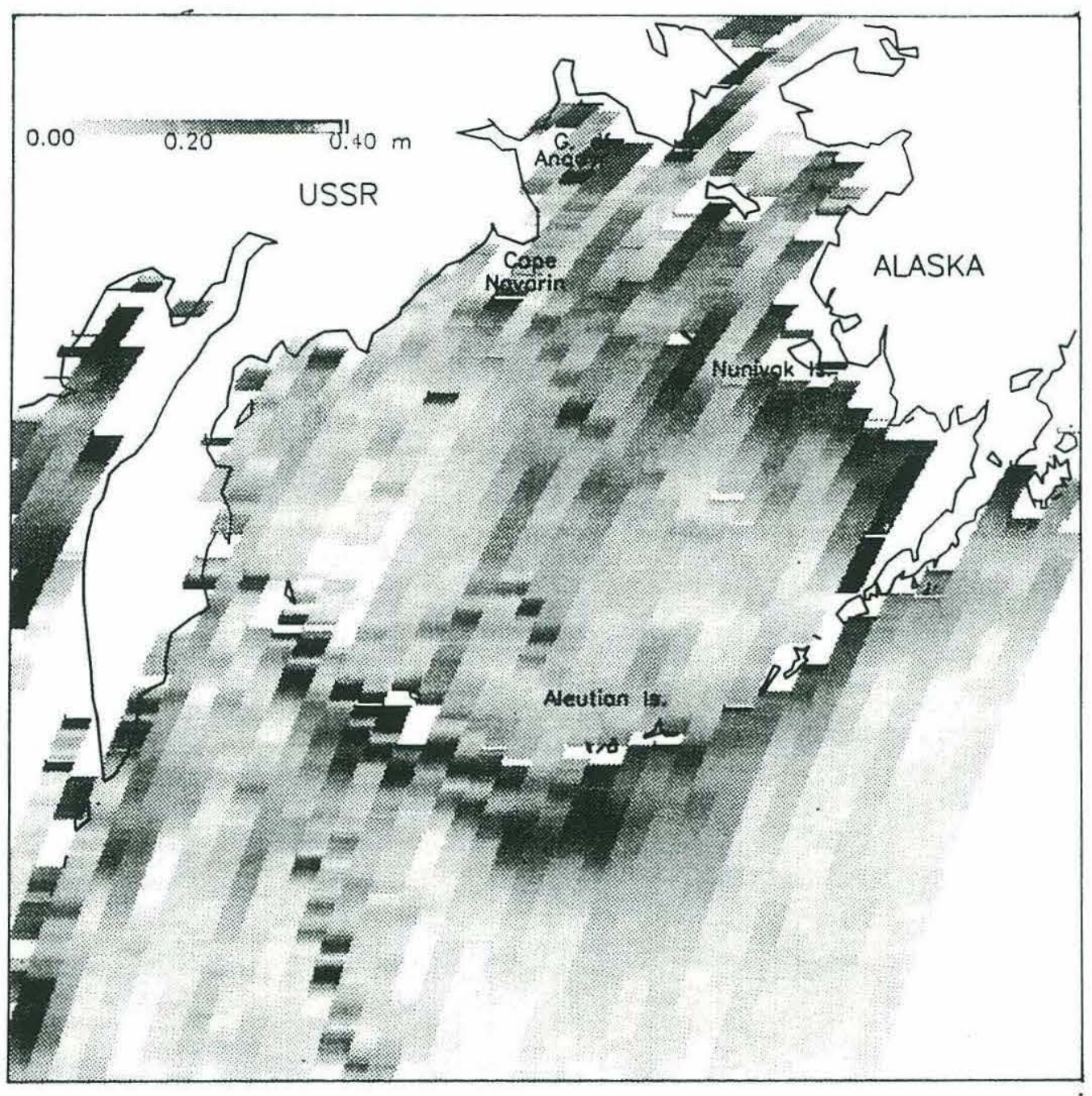

Figure 4-1: Descending track sea surface height variability 


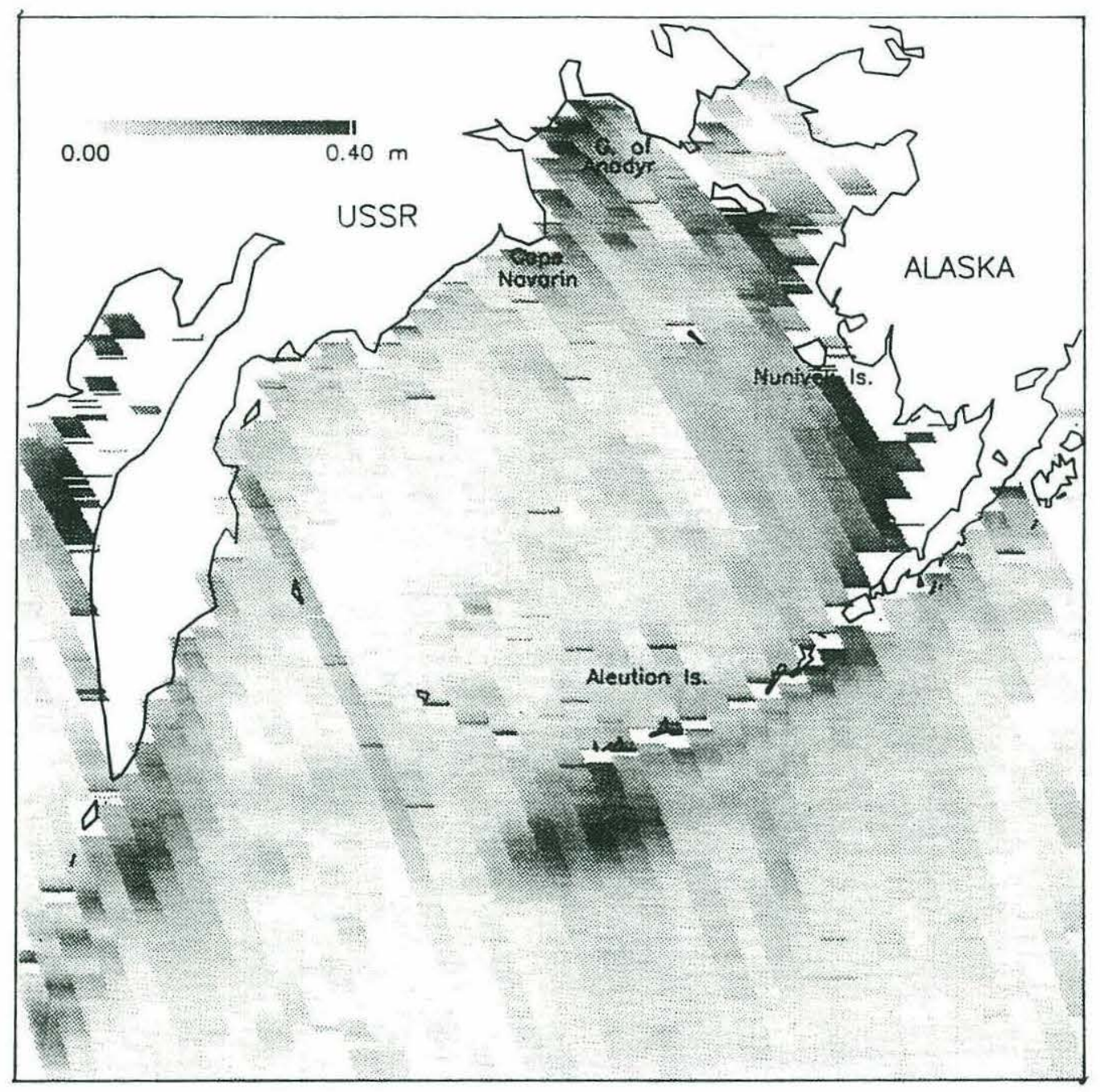

Figure 4-2: Ascending track sea surface height variability 


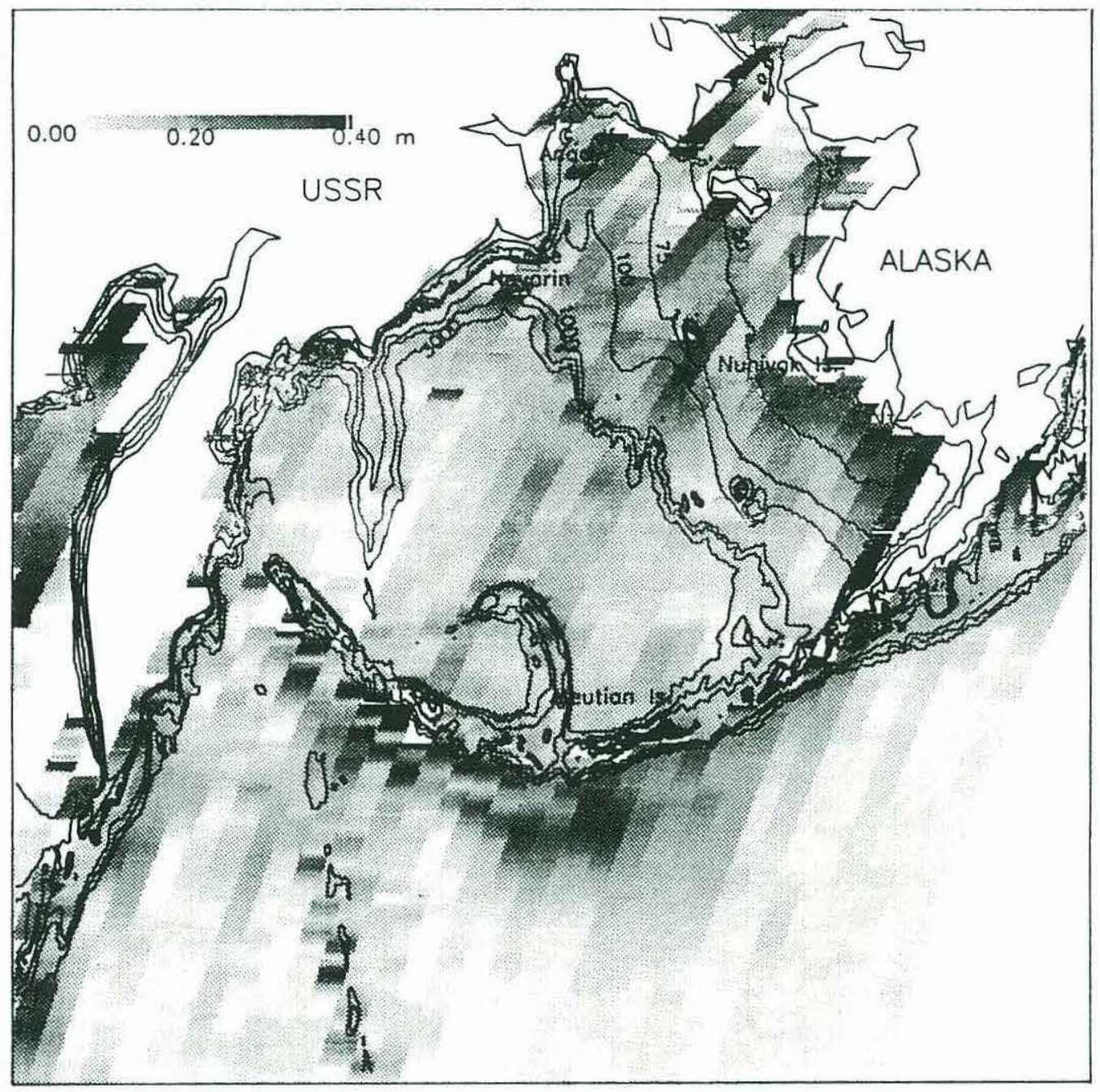

Figure 4-3: Grey shade map of sea surface variability from descending tracks. The overlain lines are bathymetry contours. Contour interval changes from $1000 \mathrm{~m}$ south - of the slope to $25 \mathrm{~m}$ north of the slope. 
reveals a clean and distinct transition, with low variability extending the entire way to the coast. The change in the Gulf of Anadyr, on the other hand, is a gradually intensifying variability, indicating the presence of true sea surface height change. The same is true of the southeastern region of variability along the Alaskan coast; just south of this region a relatively quiet environment borders the coast, while larger variability is apparent further north. This entire region is situated on the Bering shelf in water $50 \mathrm{~m}$ or less in depth. While a documented surface buoyancy current does exist in this area (Kinder, et al., 1986), the observed large amplitude tides and the lack of a shallow water tide model to determine and remove their contribution makes it unclear whether the variability in this area is due to coastal currents. The regions of approximately 0.35 $\mathrm{m}$ rms variability in the Gulf of Anadyr similarly occur in water less than $75 \mathrm{~m}$ deep. Because the Schwiderski corrections can be considered reliable only to $100 \mathrm{~m}$ depth, the variability here may also be due to tides. The shelf on this side is not nearly as broad, however, and depths increase more rapidly, so that in areas deeper than $75 \mathrm{~m}$ variability values may be treated with more confidence. This higher variability region corresponds to the path of the western boundary current (Kinder et al., 1986). The combined information from the two variability maps, supports the general circulation scheme proposed by Kinder et al. in all but one respect: the proposed division of the slope current into a northeastward and southwestward flow just south of Cape Navarin. Evidence for the northeastward flow, which becomes the western boundary current, is suggested by the region of higher variability that begins just south of Cape Navarin and extends through the Gulf of Anadyr. No support for the southwest branch, however, is seen in the variability maps. A final feature to note from the variability maps is the difference between variability in the ascending and descending maps. The slope current, visible in the descending profiles, is not as apparent as in the ascending ones. Likewise, the Gulf of Anadyr variability noticed on the ascending map is missing on the descending map. These differences are a result of the fact that only alongtrack height is being measured. Because the proposed path of the western boundary current runs parallel to the descending subtracks, sea surface height remains relatively constant along track and little change appears in profiles. The ascending profiles, however, run 
nearly perpendicular to the current. Because surface currents are, to good a approximation, in geostrophic balance, they are maintained by horizontal pressure gradients and, through the hydrostatic relation, manifested as changes in height. Thus, as the repeat profiles cross the current, they indicate a relatively sudden change in height.

\subsection{Discussion of Residual Profiles}

An example of a set of collinear passes along track d045 before and after the two-step orbit error algorithm is plotted in Figure 4-4. This track, along with tracks d131 and d174, has been chosen as a representative track for further discussions of descending track characteristics because of its length, large number of repeat passes, and central location in the Bering Sea. All three profiles exhibit oceanographic and geoid features. The first of these features is located at $60.5^{\circ} \mathrm{N}$ on d045, $59^{\circ} \mathrm{N}$ on d131 (Figure 4-5) and $58.5^{\circ} \mathrm{N}$ on track d174 (Figure 4-6), positions which concide closely with the proposed position of the Bering slope current. Both the $\mathrm{d} 131$ residuals and the d174 residuals contain a gap in data located at $53.5^{\circ} \mathrm{N}$ and $52.5^{\circ} \mathrm{N}$ respectively, which marks the location of the Aleutian Island arc and trench. Because geoid contamination often causes large data spikes, height data were eliminated here by the editing process. The strong contribution to sea surface variability by geoid contamination is depicted Figures 4-4, bottom plot. Some regions with lesser geoid contamination were undoubtedly included in the height profiles. Between the Aleutian trench and the slope current, at $55^{\circ} \mathrm{N}$, is another feature of interest, which is most clearly visible in the $\mathrm{d} 174$ profiles. No oceanographic or bathymetric features were expected in this region. Examination of the contour map in Figure 4-3 revealed that this feature coincides with the location of the "arm" of shallow water discussed in Section 2.1 which is probably due to geoid contamination.

\subsection{Further Tidal Analysis}

Although the removal of the orbit error and mean sea surface (Section 1.2) should have eliminated any long wavelength variations, such as residual deep ocean tides, 

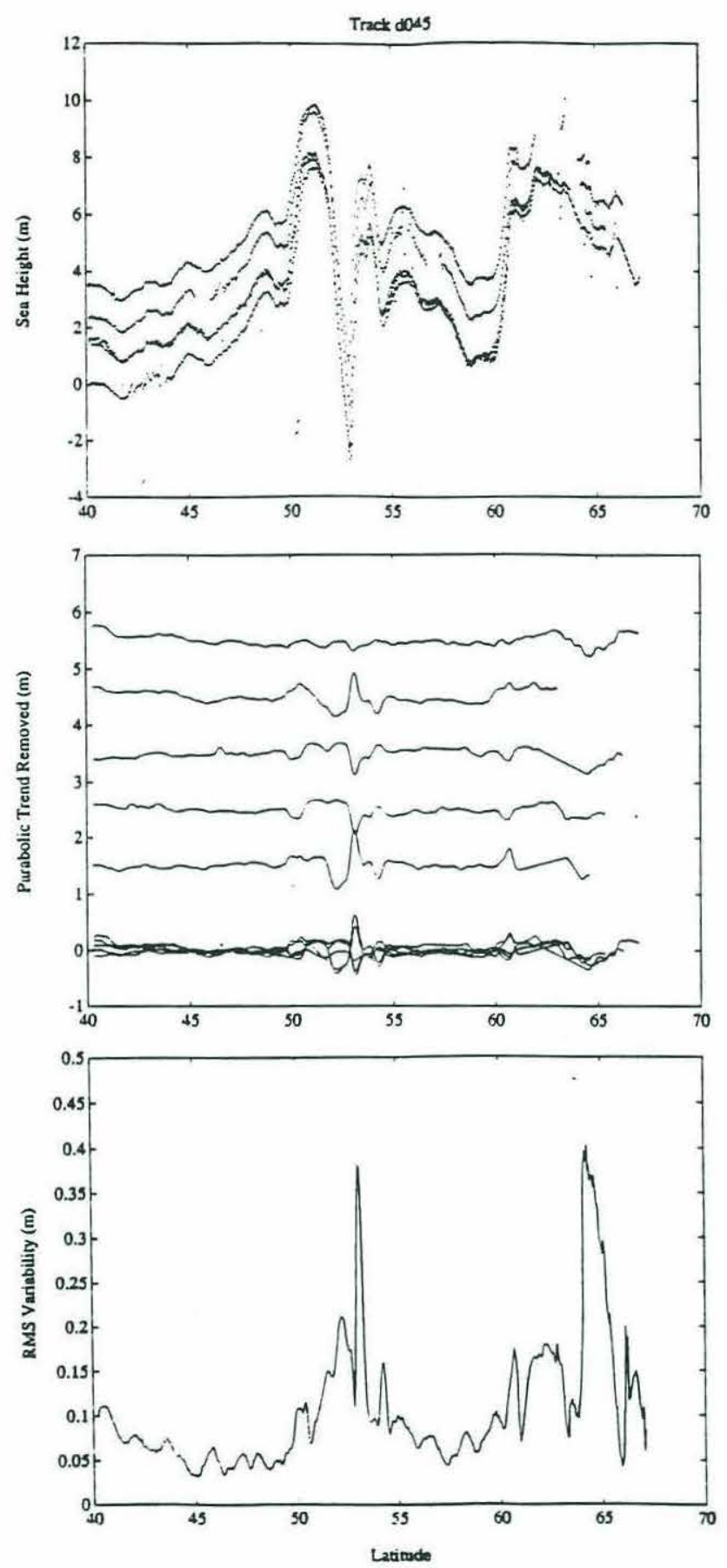

Figure 4-4: Analysis of five collinear altimeter profiles collected along groundtrack d045. (a) sea surface height relative to reference ellipsoid. (b) profiles after removal of orbit error and mean sea surface. (c) rms variability around the mean. 
Orbit d131 Residuals

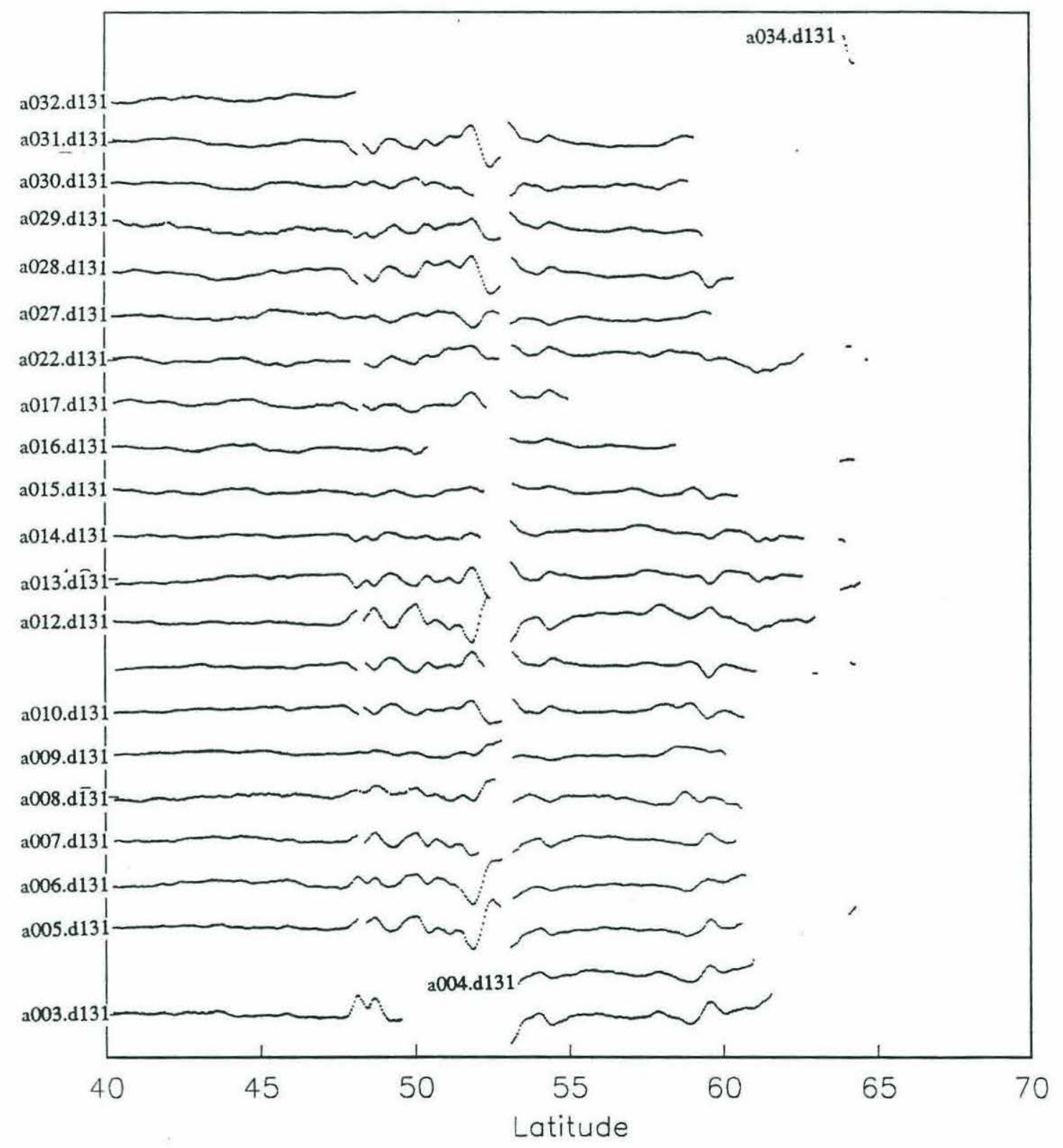

Figure 4-5: Plot of d131 Residuals 


\section{Orbit d174 Residuals}

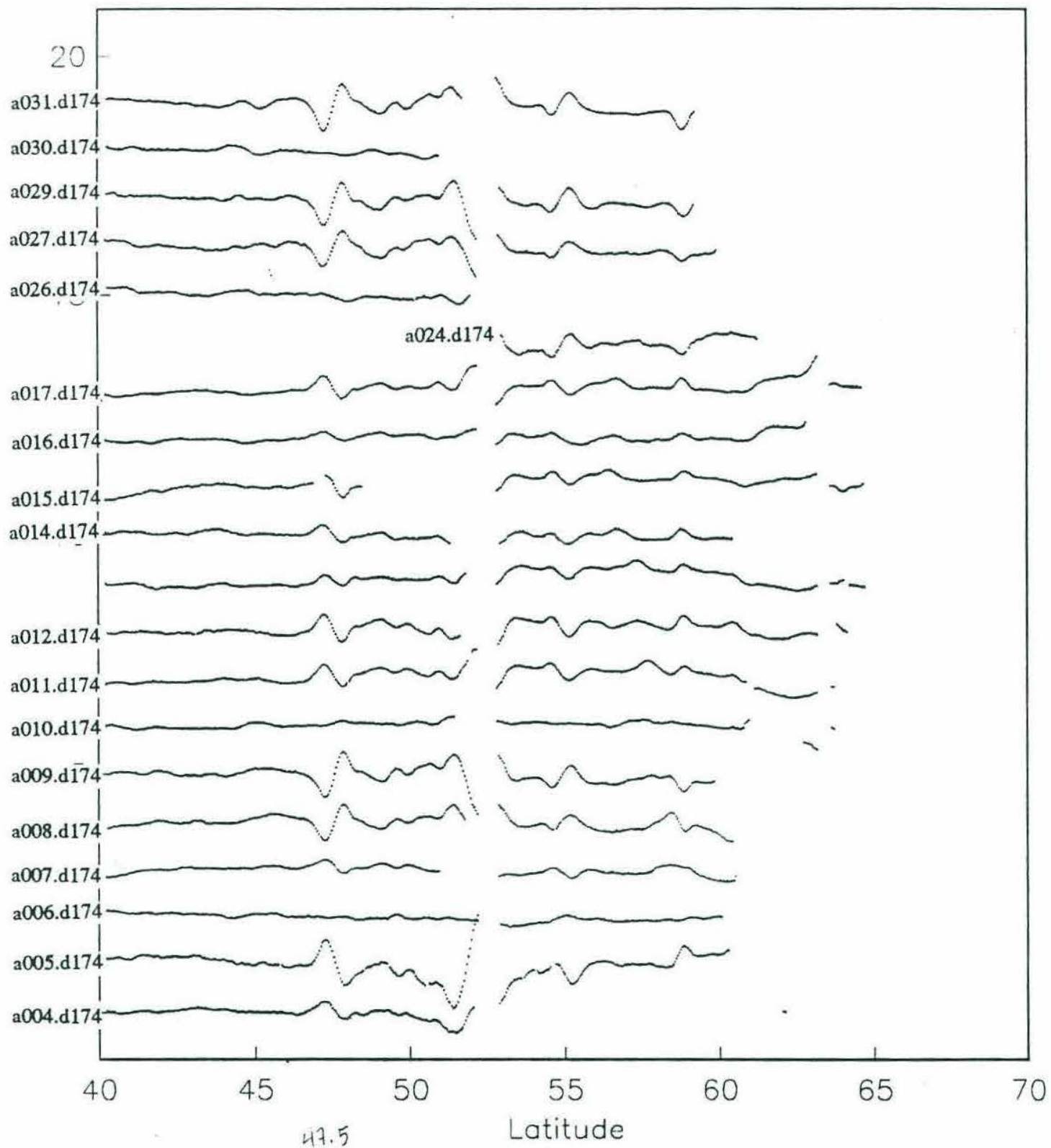

Figure 4-6: Plot of d174 Residuals 


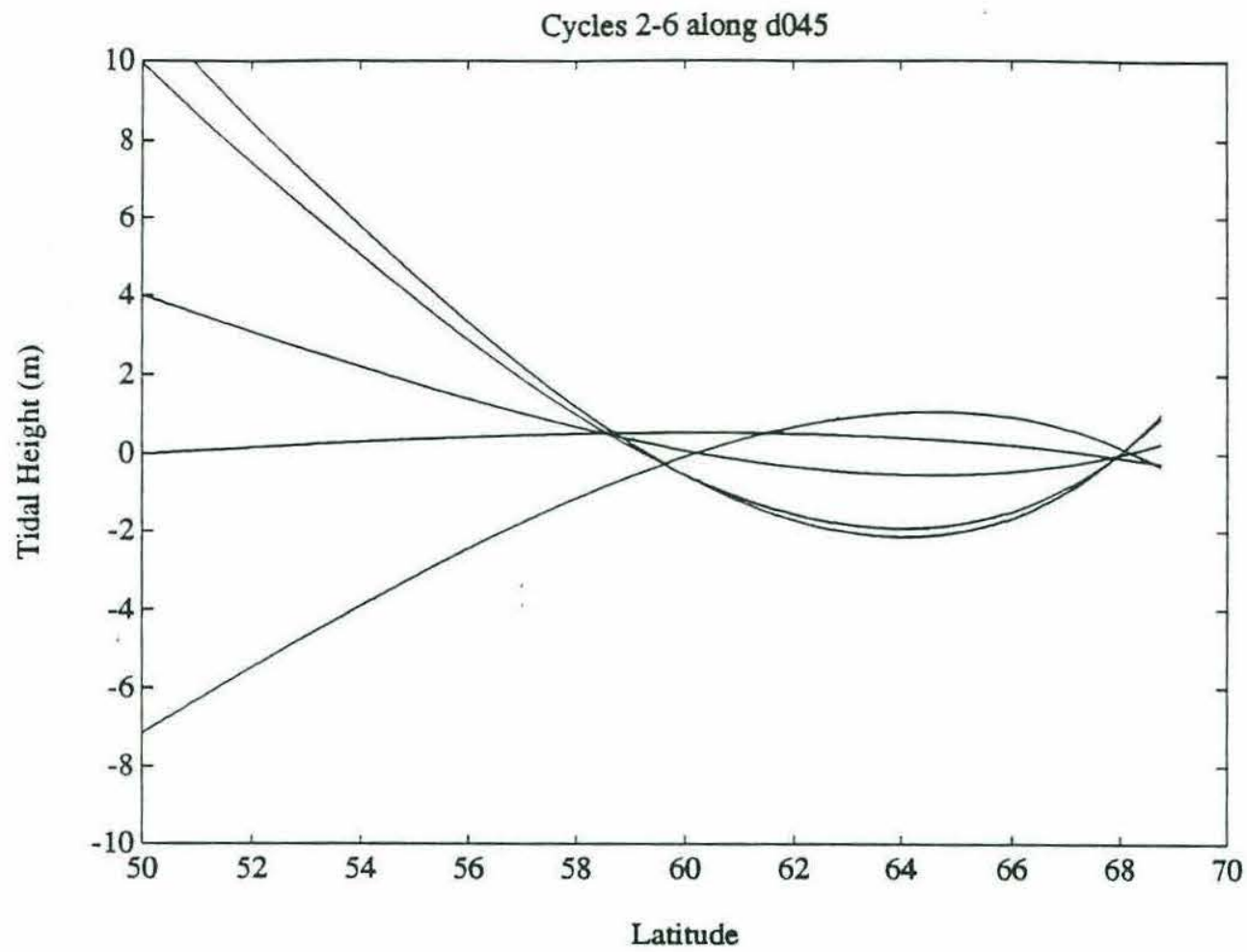

Figure 4-7: Plots of tidal amplitude along subtrack d045 for times corresponding to the first four repeat cycles along track d045. Notice the long wavelength character of the tides.

possible contributions by shorter-scale tidal signals remain in the height data. To further investigate this problem, Mofjeld's Western North Atlantic tidal model (1975) was modified for use in the Bering Sea. The model spatially interpolates harmonic constants from three reference stations to obtain constants at any other given location. From these constants the daily and semi-daily tides can be predicted. Stations LD10A, NC19C and LD15A (Figure 2-2) were chosen as the three reference stations since all three lie close to the subtrack of descending orbit d045. Tidal amplitudes were computed along the subtrack for those times corresponding to each pass. The first four such series, (Figure 4-7), suggest that tidal amplitude varies more in the southern part of the region than in the northern. If this model of the tides in the Bering Sea is accurate, most of the tidal signal would have been removed along with the orbit error, 


\begin{tabular}{|l|c|c|c|c|}
\hline $\begin{array}{c}\text { Reference } \\
\text { Station }\end{array}$ & $\begin{array}{c}\text { Station } \\
\text { Location }\end{array}$ & $\begin{array}{c}\text { Closest Alongtrack } \\
\text { Location }\end{array}$ & $\begin{array}{c}\text { Tidal } \\
\text { Variability } \\
(\mathrm{m})\end{array}$ & $\begin{array}{c}\text { Total SSH } \\
\text { Variability } \\
(\mathrm{m})\end{array}$ \\
\hline \multicolumn{5}{|c|}{ Subtrack d045 } \\
\hline LD10A & $65.5^{\circ} \mathrm{N} 168.6^{\circ} \mathrm{W}$ & $65.7^{\circ} \mathrm{N} 168.7^{\circ} \mathrm{W}$ & 0.337 & 0.088 \\
$\mathrm{NC} 19 \mathrm{C}$ & $64.0^{\circ} \mathrm{N} 172.3^{\circ} \mathrm{W}$ & $64.3^{\circ} \mathrm{N} 172.4^{\circ} \mathrm{W}$ & 0.148 & 0.374 \\
$\mathrm{LD} 15 \mathrm{~A}$ & $60.7^{\circ} \mathrm{N} 178.9^{\circ} \mathrm{W}$ & $61.2^{\circ} \mathrm{N} 179.0^{\circ} \mathrm{W}$ & 0.576 & 0.113 \\
\hline \multicolumn{5}{|c}{ Subtrack a120 } \\
\hline BC3 & $55.0^{\circ} \mathrm{N} 165.2^{\circ} \mathrm{W}$ & $55.0^{\circ} \mathrm{N} 165.0^{\circ} \mathrm{W}$ & 0.294 & 0.171 \\
$\mathrm{BC} 4$ & $58.6^{\circ} \mathrm{N} 168.2^{\circ} \mathrm{W}$ & $58.3^{\circ} \mathrm{N} 169.4^{\circ} \mathrm{W}$ & 0.119 & 0.123 \\
$\mathrm{BC} 20$ & $60.4^{\circ} \mathrm{N} 171.0^{\circ} \mathrm{W}$ & $60.2^{\circ} \mathrm{N} 172.4^{\circ} \mathrm{W}$ & 0.452 & 0.150 \\
\hline
\end{tabular}

Table 4.1: Comparison of Tidal variability with total sea surface height variability at stations along descending track d0145 and ascending track a120

because of the long wavelength nature of the tidal signal. To check for any residual mesoscale signal I processed the tidal series in a fashion similar to the collinear analysis used on the height data. Tidal amplitudes were computed at each of the three original reference stations at times corresponding to the repeat passes of the altimeter along subtrack d045 and at three new reference stations, BC3, BC4, and BC20, whose positions closely approximated locations along subtrack a120. Each set of three station locations was treated as a set of positions along a "track" that connected the three stations. The tidal amplitudes for each time at the three stations were spatially averaged to produce a mean amplitude which was then subtracted from the original amplitudes. The series of "residual" amplitudes at each station were comparable to any residual tidal signal in the sea surface height profiles after the collinear algorithm had been applied. The tidal variability at each station was calculated and compared to the sea surface height variability of the closest alongtrack point on the corresponding subtrack, in order to determine what amount, if any, of the total sea surface height variability was contributed by tides. The results, displayed in table 3.1 , were, in most cases, inconsistent with the actual data. At station $\mathrm{BC} 4$, for example, the tidal variability of $0.119 \mathrm{~m}$ is reasonable; it accounts for a large percentage of the total measured sea surface height variability in a region noted by Pearson et al., (1981) to have large tidal amplitudes. Similarly, the value at station NC19C is sensible. However, at the remaining stations, the calculated tidal variabilities are obviously erroneous, depicting 
values greatly in excess of the total measured sea surface height variability. These discrepancies prompted a comparison of the original time series at the station locations with time series observed by Mofjeld (1984) at the same locations, in order to verify that the adapted model was accurately predicting tides. The time series in the top half of figure 4-8 were generated by the modified Mofjeld model at stations LD15A (top) and NC19C (second) at a sampling rate of once every three hours. The two at the bottom are pressure series observed at the same two stations by Mofjeld. (To obtain amplitude in centimeters multiply amplitude in millibars by 0.993$)$. The two time series for station LD15A agree quite well in both amplitude and phase. Those at station NC19C, however, while similar in absolute amplitude, do not compare in phase or periodicity. Mofjeld noted that at the more northerly stations, non-tidal pressure fluctuations grew in intensity, eventually overpowering the tidal contribution in the Bering Strait. Such fluctuations could account for the discrepancy between the series' at NC19C. However, similar comparisons at LD13A and LD14A, locations which should be free of non-tidal fluctuations, also depicted discrepancies between the observed and modeled series. I concluded from these checks that the model could not be modified to accurately predict the shallow water tides in the Bering Sea and the previous results should be viewed with suspicion. A final, more elementary check was performed on the actual GDR ocean tide correction to investigate the accuracy of the Schwiderski tidal correction in the Bering Sea. Following the method used by Campbell (1988), residual heights with and without the tidal correction were compared. The collinear algorithm was used to create a set of residual profiles without any corrections. For each uncorrected residual profile the rms alongtrack variability $\left(\sigma^{2}\right)$ was calculated, and the resulting set of $\sigma^{2}$ averaged over all the cycles to determine the mean alongtrack variability $\left(\bar{\sigma}^{2}\right)$. The sample standard deviation (SSD) of each individual $\sigma^{2}$ about $\bar{\sigma}^{2}$ was also calculated. The collinear algorithm was used a second time with the tidal correction applied to produce corrected residual profiles and similar statistics were calculated. The statistics from the corrected and uncorrected profiles were compared along six test subtracks: the two representative descending subtracks, d131 and d174 which clearly sample the slope current, and four ascending subtracks: a005, a077, a120 and a163. The ascending 

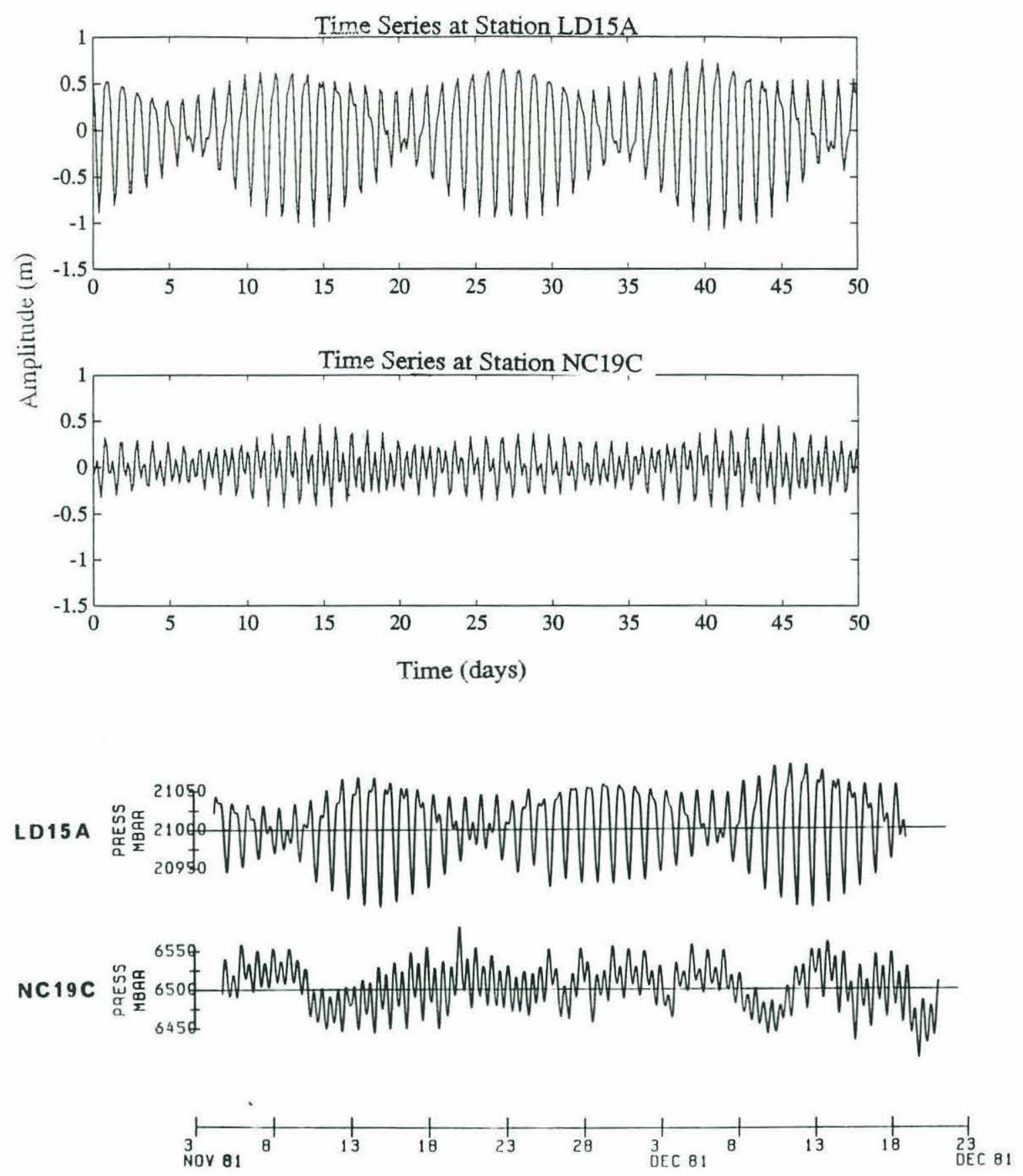

Figure 4-8: Comparison of model generated and observed tidal time series. Top two series were generated by the Mofjeld model at stations LD15A and NC19C. The bottom two are observed pressure series at the same two stations. 


\begin{tabular}{|l|lll|lll|}
\hline $\begin{array}{l}\text { Cycle } \\
\text { No. }\end{array}$ & $\begin{array}{l}\text { d131 } \\
\text { before } \\
\text { cot }\end{array}$ & $\begin{array}{l}\mathrm{d} 131 \\
\text { after } \\
\text { cot }\end{array}$ & $\begin{array}{l}\text { Percent } \\
\text { reduced }\end{array}$ & $\begin{array}{l}\text { d174 } \\
\text { before } \\
\text { cot }\end{array}$ & $\begin{array}{l}\text { d174 } \\
\text { after } \\
\text { cot }\end{array}$ & $\begin{array}{l}\text { Percent } \\
\text { reduced }\end{array}$ \\
\hline 3 & 102.4 & 98.75 & 3.56 & & & \\
4 & 144.5 & 138.1 & 4.43 & & & \\
5 & 11.11 & 10.54 & 5.13 & 1.41 & 0.74 & 47.5 \\
6 & 85.32 & 83.43 & 2.26 & 1.83 & 1.89 & -3.3 \\
7 & 1.690 & 1.680 & 0.59 & 1.33 & 1.12 & 15.8 \\
8 & 36.38 & 36.34 & 0.11 & 1.39 & 1.47 & -5.7 \\
9 & & & & 1.60 & 1.54 & 3.7 \\
10 & 96.91 & 96.25 & & & & \\
11 & 92.43 & 95.76 & -3.60 & 0.99 & 1.07 & -55.6 \\
12 & 98.26 & 99.83 & -1.60 & 0.83 & 0.98 & 18.1 \\
13 & 82.78 & 83.85 & -1.29 & 0.94 & 2.31 & -146.0 \\
14 & 90.31 & 92.73 & -2.68 & 0.83 & 1.32 & 285.0 \\
15 & 12.31 & 12.45 & -1.14 & 2.96 & 3.01 & 1.69 \\
16 & & & & 0.75 & 0.76 & -1.3 \\
17 & & & & 3.84 & 3.02 & 21.3 \\
22 & 4.44 & 2.08 & 53.2 & & & \\
24 & & & & 1.59 & 1.19 & 25.2 \\
27 & & & & 1.86 & 1.70 & 8.6 \\
28 & 1.06 & 0.950 & 10.38 & & & \\
\hline $\bar{\sigma}$ & 57.46 & 56.98 & $* 0.80$ & 1.58 & 1.58 & $* 0.00$ \\
std & 47.17 & 46.70 & & 0.84 & 0.72 & \\
\hline
\end{tabular}

Table 4.2: Alongtrack RMS variability of profiles about the mean before tidal correction (before cot) and after the correction has been applied (after cot). Values for track d131 are on the left, d174 on the right. Values are in $\mathrm{cm}$. The starred values are average percent reduction over the entire set of repeats.

subtracks were also chosen for length, location coverage and, more importantly, because these subtracks cross the western boundary current position discussed in the previous section. Along subtrack d131, 15 repeat passes were available for analysis, and along subtrack d174, 14 were analyzed. Each of the ascending subtrack sets consisted of 35 repeat passes; to conserve time and space, the first 20 passes along each track ( a time span of approximately one year) were analyzed. Results for the descending orbits are tabulated in Table 4.2. Ascending subtracks a005 and a077 are listed in Table 4.3 and tracks a120 and a163 in Table 4.4 .

In order to judge the effectiveness of the Schwiderski tidal correction from the statistics in Tables 4.2 through 4.4 it is important to understand the relationship be- 


\begin{tabular}{|c|c|c|c|c|c|c|}
\hline $\begin{array}{l}\text { Cycle } \\
\text { No. }\end{array}$ & $\begin{array}{l}\text { a005 } \\
\text { before } \\
\text { cot }\end{array}$ & $\begin{array}{l}\text { a005 } \\
\text { after } \\
\text { cot }\end{array}$ & $\begin{array}{l}\text { Percent } \\
\text { reduced }\end{array}$ & $\begin{array}{l}\text { a077 } \\
\text { before } \\
\text { cot }\end{array}$ & $\begin{array}{l}\mathrm{a} 077 \\
\text { after } \\
\text { cot }\end{array}$ & $\begin{array}{l}\text { Percent } \\
\text { reduced }\end{array}$ \\
\hline 0 & 16.39 & 2.680 & 83.6 & 17.40 & 0.700 & 59.8 \\
\hline 1 & 0.340 & 0.320 & 5.89 & 0.230 & 0.370 & -60.9 \\
\hline 2 & 1.780 & 2.240 & -25.8 & 6.370 & 1.640 & 74.3 \\
\hline 3 & 1.650 & 1.150 & 30.3 & 6.070 & 1.300 & 78.6 \\
\hline 4 & 7.000 & 4.490 & 35.8 & 3.910 & 0.540 & 86.2 \\
\hline 5 & 8.780 & 0.640 & 92.7 & 4.080 & 1.480 & 63.7 \\
\hline 6 & 4.780 & 0.730 & 84.6 & 4.920 & 2.620 & 46.7 \\
\hline 7 & 2.840 & 1.000 & 64.8 & 1.180 & 1.010 & 14.1 \\
\hline 8 & 13.26 & 3.630 & 72.6 & 2.030 & 0.560 & 72.4 \\
\hline 9 & 7.220 & 2.620 & 63.7 & 2.460 & 0.550 & 77.6 \\
\hline 10 & 2.500 & 2.030 & 18.8 & 3.830 & 0.780 & 79.6 \\
\hline 11 & 7.860 & 3.790 & 51.8 & 7.120 & 1.160 & 83.7 \\
\hline 12 & 2.970 & 0.280 & 90.6 & 2.050 & 0.790 & 61.5 \\
\hline 13 & 3.150 & 1.290 & 59.0 & 0.630 & 0.390 & 38.1 \\
\hline 14 & 0.890 & 1.10 & -23.6 & 1.350 & 1.180 & 12.6 \\
\hline 15 & 0.760 & 1.480 & -94.7 & 0.370 & 0.460 & -24.3 \\
\hline 16 & 3.080 & 1.950 & 36.7 & 2.720 & 0.750 & 72.4 \\
\hline 17 & 1.840 & 1.050 & 42.9 & 2.460 & 0.580 & 76.4 \\
\hline 18 & 16.03 & 4.52 & 71.8 & 0.910 & 1.160 & -27.5 \\
\hline 19 & 0.270 & 0.210 & 22.2 & 2.440 & 0.500 & 79.5 \\
\hline 20 & 13.33 & 5.840 & 56.0 & 1.310 & 1.310 & 0 \\
\hline $\bar{\sigma}$ & 5.550 & 2.050 & $* 63.9$ & 2.780 & 0.950 & *65.8 \\
\hline std & 5.090 & 1.550 & & 1.980 & 0.530 & \\
\hline
\end{tabular}

Table 4.3: Same as Figure 4.2 except for tracks a005 and a077 


\begin{tabular}{|c|c|c|c|c|c|c|}
\hline Cycle & Orbit a120 & Orbit 120 & Percent & Orbit a163 & Orbit a163 & Percent \\
\hline No. & before cot & after cot & reduced & before cot & after cot & reduced \\
\hline 0 & 0.610 & 0.220 & 63.9 & 0.530 & 0.280 & 47.2 \\
\hline 1 & 6.460 & 1.340 & 79.2 & 5.900 & 2.860 & 51.5 \\
\hline 2 & 4.190 & 2.970 & 29.1 & 0.820 & 1.050 & -28.0 \\
\hline 3 & 0.290 & 0.880 & -200.0 & 2.030 & 0.750 & 63.1 \\
\hline 4 & 4.030 & 2.190 & 45.6 & 2.450 & 0.760 & 69.0 \\
\hline 5 & 0.600 & 0.540 & 10.0 & 2.410 & 0.680 & 71.8 \\
\hline 6 & 2.590 & 1.040 & 69.3 & 15.20 & 2.390 & 84.3 \\
\hline 7 & 4.960 & 0.640 & 87.1 & 15.49 & 1.440 & 90.7 \\
\hline 8 & 16.59 & 2.270 & 86.3 & 6.920 & 1.170 & 83.1 \\
\hline 9 & 12.68 & 3.150 & 75.2 & 6.670 & 1.580 & 76.3 \\
\hline 10 & 9.340 & 2.650 & 71.6 & 0.510 & 0.270 & 47.1 \\
\hline 11 & 3.490 & 1.130 & 67.6 & 9.420 & 0.810 & 91.4 \\
\hline 12 & 2.370 & 1.400 & 40.9 & 4.750 & 0.720 & 84.8 \\
\hline 13 & 4.890 & 1.820 & 62.7 & 7.800 & 0.890 & 88.6 \\
\hline 14 & 3.030 & 1.020 & 66.3 & 11.88 & 2.160 & 81.8 \\
\hline 15 & 2.400 & 1.020 & 57.5 & 3.720 & 1.060 & 71.5 \\
\hline 16 & 4.770 & 1.910 & 59.9 & 2.320 & 1.890 & 18.5 \\
\hline 17 & 3.000 & 1.060 & 64.7 & 5.180 & 3.450 & 33.4 \\
\hline 18 & 1.320 & 1.130 & 14.4 & 0.550 & 0.480 & 12.7 \\
\hline 19 & 4.920 & 0.740 & 84.9 & 1.070 & 2.170 & -102.8 \\
\hline 20 & 1.430 & 1.860 & -30.0 & 0.570 & 2.660 & -366.7 \\
\hline $\bar{\sigma}$ & 4.510 & 1.480 & ${ }^{*} 67.2$ & 5.060 & 1.290 & $* 74.0$ \\
\hline std & 3.930 & 0.790 & & 4.570 & 0.870 & \\
\hline
\end{tabular}

Table 4.4: Same as previous two figures only for tracks a120 and a163 
tween application of the correction and the behavior of the variability. Campbell (1988) provides a discussion on the behavior of variability in terms of coherent and incoherent power. Briefly stated, this discussion demonstrated that if the model of the tides accurately reflects the tidal contribution to the sea surface height, variability should decrease when the correction is applied. If, on the other hand, the model of the tides is inaccurate, alongtrack variability should increase. Thus, if the Schwiderski tidal correction for a particular cycle is accurate, that cycle's corrected profile should have a lower spatial variability, $\sigma^{2}$, than its uncorrected profile. If the correction is resonable over an entire set of cycles, $\bar{\sigma}^{2}$ will be lower in the corrected case than in the non-corrected case. Additionally, applying an accurate correction should make the repeat cycles in a set look more alike, resulting in a smaller standard deviation after the correction is applied. The statistics on the test tracks reveal that the tidal correction performs well overall, although it performs better on some tracks than others. (Certain tracks, such as c013.d174, c014.d174, c019.a163 and c020.a163, have such anomalously large changes in variability, that these values should be viewed suspiciously.) The correction also seems to perform better on individual ascending tracks than on the individual descending tracks. Mean alongtrack variability, $\bar{\sigma}^{2}$, decreased along each subtrack, in-

dicating that the tidal affects were well-modeled for all the subtracks examined. The average reduction was approximately $60 \%$ (Tables 4.2 through 4.4 ). Since long wavelength tidal signal is eliminated in the collinear processing and the Schwiderski model appears to perform well overall, unknown tidal contribution should be a problem only in those depths below the Schwiderski limit of approximately $100 \mathrm{~m}$.

\subsection{Application of a Gaussian Model to the Data Set}

Although the variability maps in section 4.1 provided evidence of the existence and strength of the Bering slope and western boundary currents, questions still remained concerning the nature of these currents. For instance, does the western boundary current actually supply the majority of the 1-1.5 Sv transport through the Bering Strait. The variability maps suggested that the entire slope current turned north into the western boundary current at the western coast, instead of separating into two flows 
(Kinder et al., 1986). Are the surface transports of the western boundary current and slope current consistent for this case in which the slope current must be the only source for the western boundary current? Is there a detectable seasonal cycle to either flow or a coherent cycle between the two? This section describes what answers to these questions can be determined from the GEOSAT altimeter data using a technique applied by Kelly and Gille (1989) on the Gulf Stream. Kelly and Gille (1989) (hereafter $\mathrm{K} \& \mathrm{G}$ ) demonstrated the use of a simple model for the velocity profile in determining Gulf Stream kinematics and subsequently its absolute surface geostrophic velocity and transport. Using an estimate of current width and position derived from actual height residuals along one subtrack, in conjunction with a Gaussian model for the Gulf Stream velocity profile, they computed synthetic residual height profiles. They then obtained estimates of the maximum surface velocity and surface transport by a least squares fit of the synthetics to the actual data. Their final statistics proved to be consistent with historical measurements and Gulf Stream locations obtained from infrared images over the region.

\subsubsection{Methodology}

The following method is taken from $\mathrm{K} \& \mathrm{G}$, but applied to the Bering slope current instead of the Gulf Stream. It assumes the slope current to have, to first order, a Gaussian shape of the form

$$
u(y)=a_{1} \exp \left[\frac{-\left(y-a_{2}\right)^{2}}{2 a_{3}^{2}}\right]
$$

where $u$ is the downstream velocity as a function of cross-stream location $y, a_{1}$ is the velocity maximum, $a_{2}$ is the position of the center of the slope current, and $a_{3}$ is a width parameter defined by

$$
a_{3}=\frac{L_{H M}}{2(2 \ln 2)^{1 / 2}}
$$

where $L_{H M}$ is the full-width half-maximum of the Gaussian. (Figure 4-9.) The dynamic height profile relative to some reference level is then given by the integral of (4.1),

$$
h(y)=-\frac{f}{g} \int u\left(y^{\prime}\right) d y^{\prime} .
$$


$\mathrm{u}$

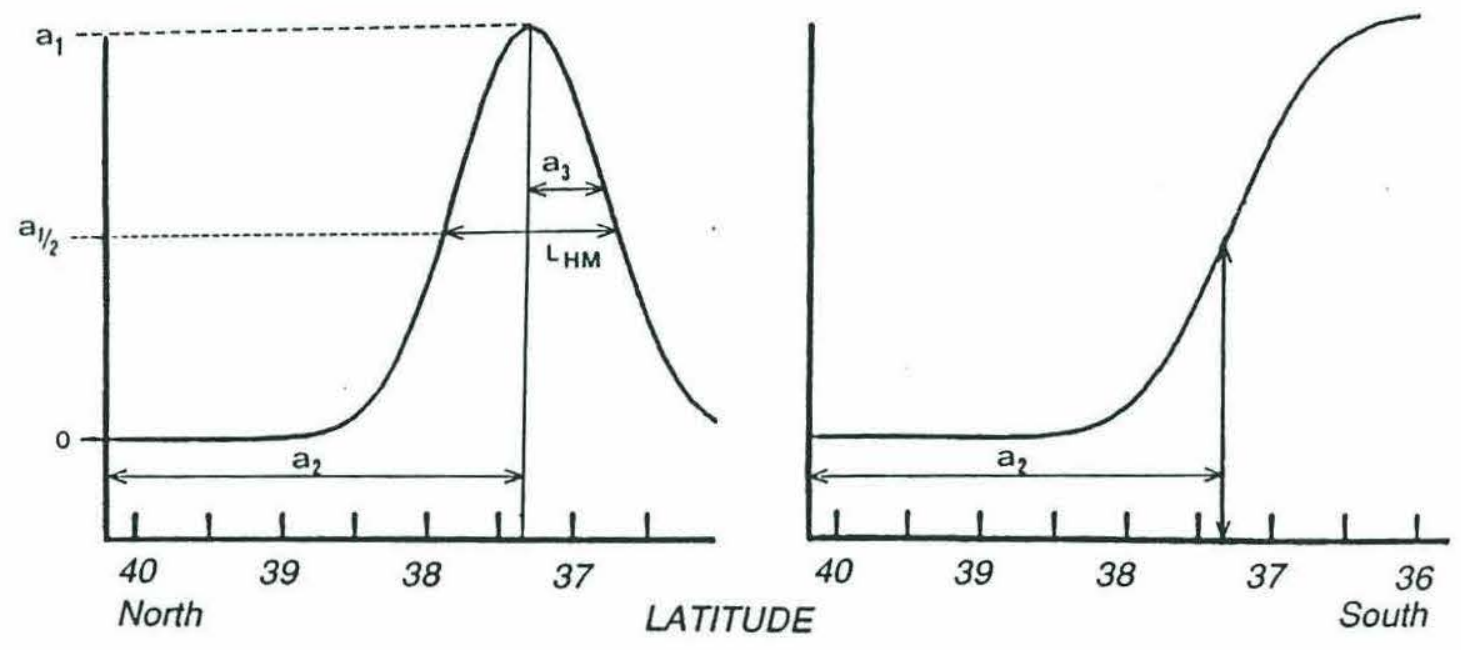

Figure 4-9: Definition sketch for Gaussian model. The velocity profile (left) depicts the maximum velocity parameter, $a_{1}$, the center location, $a_{2}$, and the width parameter, $a_{3}$. The sea surface height (right) is obtained by integrating the velocity profile (From Kelly and Gille, [1989]). 
Synthetic velocities were computed from equation (4.1) using values of $a_{2}$ and $a_{3}$ that were estimated from actual height residuals and an initial guess for the mean maximum velocity parameter, $\left\langle\widehat{a_{1}}\right\rangle$. These velocity profiles were then integrated to generate a series of synthetic height profiles, $\hat{h}(y, t)$. All of the synthetic height profiles were averaged to compute an estimated mean slope current height profile $\langle\hat{h}(y, t)\rangle$, which was added to the actual GEOSAT data residuals, $h^{\prime}(x, t)$, to produce estimated total height profiles, $\tilde{h}(x, t)$. A least squares fit of the synthetics to the total height profiles was performed over a one-degree region centered on the estimated current location for that cycle. The fit was performed by varying in turn each of the parameters $\alpha, \gamma$, and $\delta$ to minimize

$$
\sum_{y}[\tilde{h}(x, t)+\gamma-\alpha \hat{h}(y+\delta, t)]^{2}
$$

where $\gamma$ is a constant offset accounting for uncorrected orbit errors, $\delta$ is a shift allowing for errors in $a_{2}$, the estimated location, and $\alpha$ is a factor allowing for variation of the maximum velocity around its mean, defined as

$$
\alpha(t)=\frac{a_{1}(t)}{\left.<\widehat{a_{1}}\right\rangle}
$$

Based on the results of the fit, $\left\langle\widehat{a_{1}}\right\rangle$ was adjusted and the least-squares fit repeated until $\langle\alpha(t)>$ became approximately one, indicating that the average of the data series was consistent with the estimate of the average maximum velocity. The entire procedure was performed on the height residuals from the two adjacent descending tracks previously examined, d174 and d131. The two subtracks were processed individually, then combined as repeat passes over one subtrack, by shifting the position of the maximum slope location and the height residuals for cycle d174 by the average difference in $a_{2}$ between the subtracks. The decision to combine the two sets was made to improve accuracy and lengthen the series, because repeat cycles that were missing or unusable along one orbit were usually available along the other. For instance, in cycle 10 along orbit d174 (Figure 4-6) the location of the current is impossible to determine because of the lack of distinct features. Similarly, the height profile in cycle 7 has been distorted by what is probably an eddy. 


\subsubsection{Estimating the parameters}

According to $\mathrm{K} \& \mathrm{G}$, the center of the Bering slope current, $a_{2}(t)$, should be the location at which the sea surface height has the maximum positive slope. Points of relative maximum slope for each cycle were determined from simple first differences. When more than one local maximum was available, the one which kept the slope current postion relatively consistent between passes was chosen. The full-width half-maximum, $L_{H M}$, was determined subjectively from each residual as the distance between the local minimum and maximum height values bounding the region of maximum slope. These values were then converted to values of $a_{3}(t)$ using equation (4.2). Values for $a_{1}(t)$ were directly computed from results of the least-squares fit. The parameters for the combined data set are listed in table 4.5 along with calculations of surface transport $U$ given by

$$
U=(2 \pi)^{1 / 2} a_{1} a_{3}
$$

and calculations of $\Delta h$, the absolute height difference across the current.

For those repeat passes where a value was available for both orbit d174 and d131, the two values for $a_{1}$ and $a_{3}$ were averaged before calculating $\mathrm{U}$ and $\Delta h$. Those cycle numbers are noted in the table by an asterisk. Table 4.6 lists the statistics for the slope current.

\subsubsection{Discussion of Results}

\section{Parameters and Statistics}

Although the relative fluctuations in the location of the center of the slope current are large compared to the other parameters, the ratio of position variations to width, $a_{2}^{\prime} /<a_{3}>$, was only just larger than one. This ratio indicates that the current meanders a distance slightly greater than its scale width. The meander distance was initially of concern as the current must meander a distance at least comparable to its width for the iterative least squares procedure to converge ( $\mathrm{K} \& \mathrm{G}$ ). Fortunately that requirement was met and no convergence problems were encountered. When determining the Gulf Stream location, K\&G superimposed residual heights over infrared images 


\begin{tabular}{|cccccc|}
\hline $\begin{array}{c}\text { cycle } \\
\text { no. }\end{array}$ & $\begin{array}{c}a_{2} \\
\text { N lat. }\end{array}$ & $\begin{array}{c}a_{3} \\
\text { deg. lat. }\end{array}$ & $\begin{array}{c}a_{1} \\
m s^{-1}\end{array}$ & $\begin{array}{c}\mathrm{U} \\
10^{5} \mathrm{~m}^{2} \mathrm{~s}^{-1}\end{array}$ & $\begin{array}{c}\Delta h \\
\mathrm{~m}\end{array}$ \\
\hline \hline 3 & 59.39 & 0.217 & 0.773 & 0.600 & 0.764 \\
4 & 59.25 & 0.197 & 0.870 & 0.612 & 0.780 \\
5 & 59.38 & 0.188 & 0.872 & 0.586 & 0.748 \\
6 & 59.25 & 0.217 & 0.755 & 0.587 & 0.748 \\
7 & 59.34 & 0.157 & 0.878 & 0.495 & 0.631 \\
8 & 59.38 & 0.128 & 0.716 & 0.336 & 0.428 \\
9 & 59.82 & 0.158 & 0.755 & 0.426 & 0.543 \\
10 & 59.71 & 0.215 & 0.755 & 0.581 & 0.740 \\
11 & 59.76 & 0.187 & 0.756 & 0.506 & 0.645 \\
12 & 59.44 & 0.184 & 0.720 & 0.475 & 0.605 \\
13 & 59.76 & 0.157 & 0.878 & 0.465 & 0.592 \\
14 & 59.76 & 0.158 & 0.774 & 0.436 & 0.555 \\
15 & 59.76 & 0.168 & 0.633 & 0.379 & 0.483 \\
16 & 59.50 & 0.159 & 0.716 & 0.409 & 0.521 \\
17 & 59.45 & 0.119 & 1.040 & 0.443 & 0.564 \\
22 & 59.71 & 0.098 & 0.761 & 0.265 & 0.338 \\
24 & 59.92 & 0.198 & 0.654 & 0.462 & 0.589 \\
27 & 59.82 & 0.139 & 0.639 & 0.317 & 0.404 \\
28 & 59.76 & 0.176 & 0.801 & 0.504 & 0.642 \\
\hline
\end{tabular}

Table 4.5: Bering slope current model parameters for combined data set

\begin{tabular}{|l|c|l|l|l|}
\hline Parameter & units & $\begin{array}{l}\text { mean } \\
\langle a\rangle\end{array}$ & $\begin{array}{l}\text { standard } \\
\text { deviation } \\
\sigma\end{array}$ & $\begin{array}{l}\text { ratio } \\
\sigma /<a\rangle\end{array}$ \\
\hline$a_{2}$ & N latitude & 59.14 & 0.196 & $1.15\left(a_{2}^{\prime} /<a_{3}>\right)$ \\
$a_{3}$ & degrees latitude & 0.170 & 0.033 & 0.194 \\
$a_{1}$ & $\mathrm{~ms}^{-1}$ & 0.788 & 0.088 & 0.112 \\
$\mathrm{U}$ & $10^{5} \mathrm{~m}^{2} \mathrm{~s}^{-1}$ & 0.477 & 0.095 & 0.199 \\
$\Delta h$ & $\mathrm{~m}^{2} \mathrm{~s}^{-1}$ & 0.596 & 0.124 & 0.208 \\
\hline
\end{tabular}

Table 4.6: Parameter statistics for Bering Slope Current 
from the Advanced Very High Resolution Radiometer (AVHRR). Since no such images were available over the slope current region for the time involved, an error in slope current position could have resulted from improperly choosing the maxima assumed to correspond to the center of the current. While choosing the point most temporally consistent worked well most of the time, ambiguous profiles such as cycle 8 along track d131 (Figure 4-5) remained. In such cases, the same repeat along the second orbit was examined for further insight. Cycle 8 along track d174 (Figure 4-6) revealed a deepening of the second indentation, thus the second, positive slope at approximately $59.5^{\circ} \mathrm{N}$, although shallower than the slope at $58.5^{\circ} \mathrm{N}$, was selected as the center location. The relative size fluctuations in the width parameter, $a_{3}$, were small. The mean alongtrack width was $0.170^{\circ}$ latitude or $24 \mathrm{~km}$, surprisingly almost as large as the width parameter K\&G calculated for the Gulf Stream. The mean value of the maximum velocity was $0.788 \mathrm{~m} / \mathrm{s}$ with a standard deviation of $0.088 \mathrm{~m} / \mathrm{s}$. As mention in $\mathrm{K} \& \mathrm{G}$, these values are determined from the least squares fit, thus depend on the convergence of the iterative procedure, the accuracy of the estimated parameters, and the applicability of the Gaussian model to the Bering Slope current. No observations exist to establish the appropriateness of the Gaussian assumption; however, the model appeared functional and provided results reasonable in the overall circulation scheme of the western Bering Sea, as discussed in the following section.

Time series of the computed parameters show some correlations among the model parameters and the surface transport (Figure 4-10). The alongtrack width does not fluctuate greatly, undergoing a slight decrease between January and March 1987, then increasing again in April 1987. The maximum surface velocity fluctuates mildly between January and March 1987, before levelling out for several months. It fluctuates considerably again between approximately the end of May and September 1987. Surface transport, which is the product of these two variables, reflects general trends in both, rather than being dominated by either during any time frame. However, the large dip in transport does concide with the slighter dip in the width parameter between January and March 1987. After reaching its local peak in April 1987, the transport gradually decreases through the summer months. The sharp increase in surface velocity between 
cycles 15 and 17 is not strongly reflected in the transport, probably because the width is decreasing during the same period.

\subsection{The Circulation Puzzle}

Analysis of altimeter data in the northwestern region of the Bering Sea indicated that instead of bifurcating at Cape Navarin, the entire Bering slope current turns north, flowing along the coast into the Gulf of Anadyr. The analysis of the Bering slope current discussed in the previous section provided a parameterization of this current and its mean, including estimates of the surface geostrophic velocity and transport, before it turns northward. Ideally, a similar analysis could be performed on the profiles crossing the western boundary current and the results from the two analyses compared to determine any correlations between the two currents. The residual height profiles along the ascending tracks, however, do not depict the distinct "bump" characteristic of a jet-like current. Instead they show a gradual sea surface height change toward the coast, as seen in the profiles along track a120 (Figure 4-11). The large negative slopes toward the coast or higher latitudes are indicative of intense northerly flow; shallower or positive slopes reflect a weakening or reversal in the flow. The shape of the profiles imply a current better represented by a simple sea surface gradient than a jet, and thus not conducive to the Gaussian velocity representation: An alternative examination of the fluctuation in residual sea surface height was conducted by measuring the change across the estimated width of the current, $\Delta h^{\prime}$. This width was estimated for each subtrack as the distance between the point at which the subtrack intersected the $75-\mathrm{m}$ depth contour, to exclude the extreme shallow water regions where the tidal contribution is undetermined, and the point of transition from relatively low surrounding variability to the higher levels that signify the current position. Table 4.7 provides a listing of the five subtracks examined, the distance over which the height change was measured and the value of that height change. Also included in the table are the mean height fluctuations and standard deviation for each cycle, and, in the last column, a spatial mean for each repeat cycle across the five subtracks. As seen in Table 4.7, the spatial mean values for cycles $20,22,32$, and 33 are calculated from values available along only 

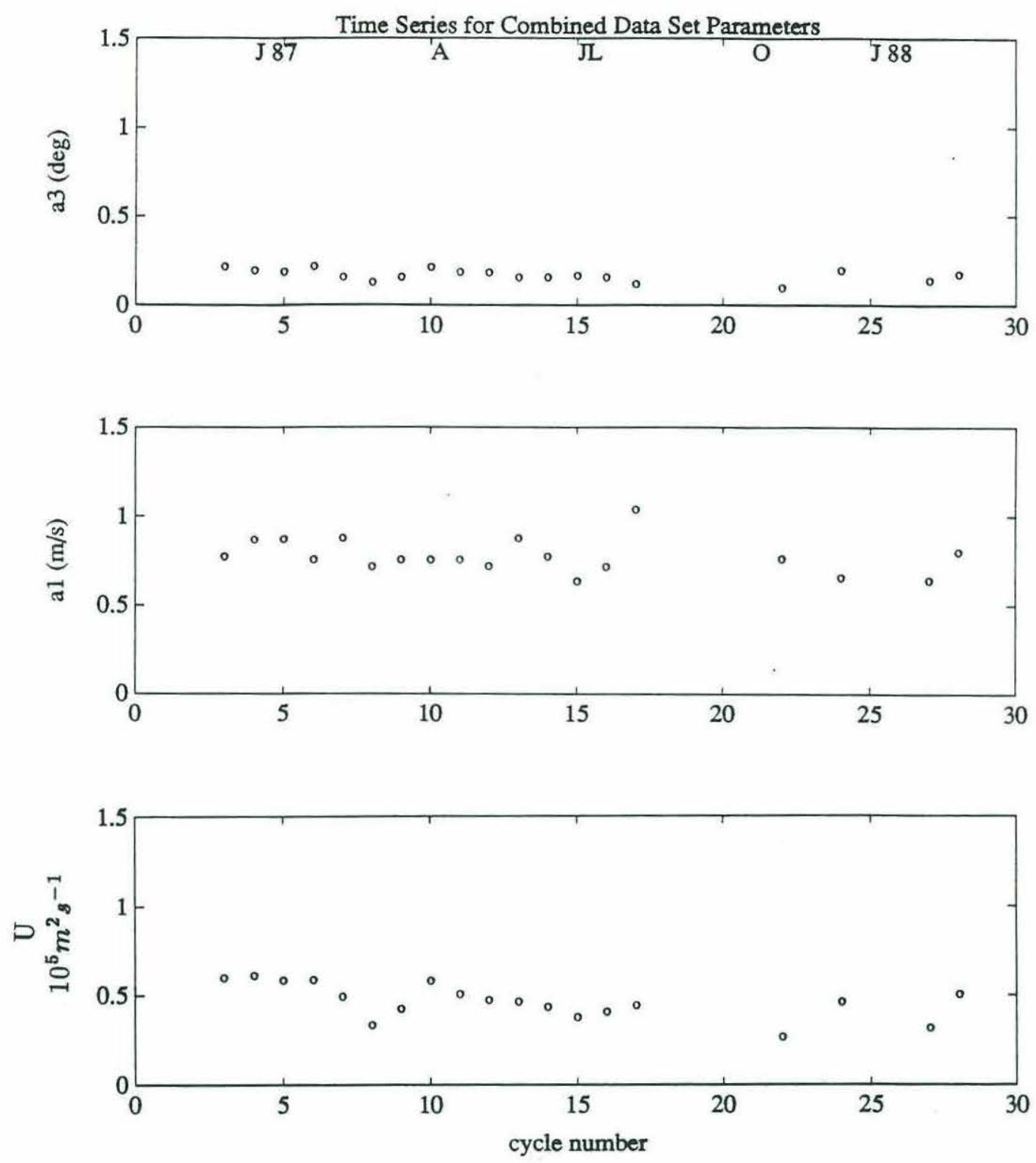

Figure 4-10: Time series of model parameters and surface transport. The Bering Slope current width parameter, $a_{3}$, in degrees latitude (top), maximum velocity, $a_{1}$, (middle), and integrated surface transport, U, (bottom). 

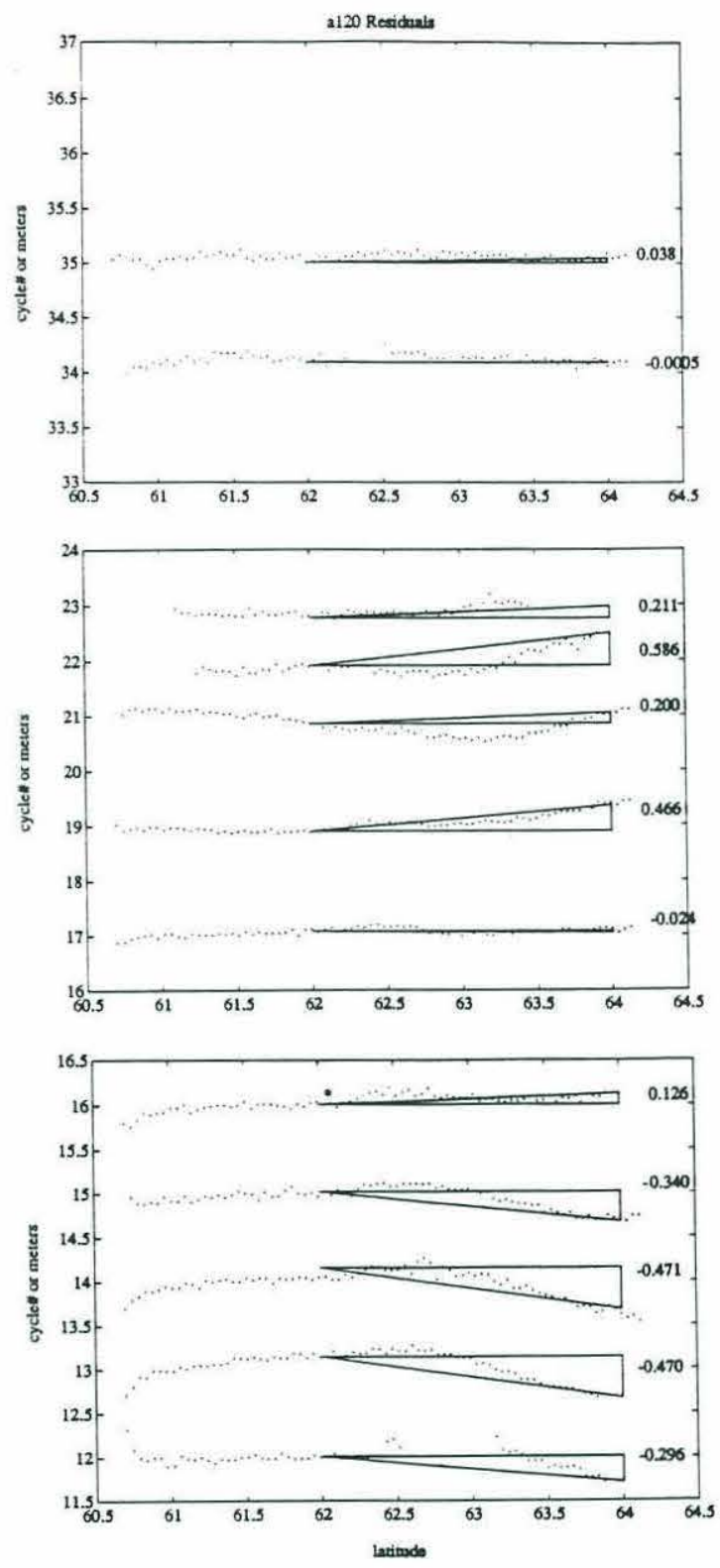

Figure 4-11: Residual height profiles along subtrack a120. The change in sea surface height at the northern end of each profile relative to $62^{\circ} \mathrm{N}$ along this subtrack was also seen along the four other ascending tracks. It indicates the strength of the western boundary current fluctuations. 


\begin{tabular}{|c|rrrrr|r|}
\hline $\begin{array}{c}\text { cycle } \\
\text { no. }\end{array}$ & $\begin{array}{rrrc}\text { Track } \\
\mathrm{a} 005\end{array}$ & $\begin{array}{r}\text { Track } \\
\mathrm{a} 077\end{array}$ & $\begin{array}{r}\text { Track } \\
\mathrm{a} 120\end{array}$ & $\begin{array}{r}\text { Track } \\
\mathrm{a} 163\end{array}$ & $\begin{array}{r}\text { Track } \\
\text { a206 }\end{array}$ & $\begin{array}{r}\text { spatial } \\
\text { average }\end{array}$ \\
\hline 12 & -0.176 & & -0.296 & -0.350 & 0.145 & -0.167 \\
13 & 0.480 & -0.294 & -0.470 & -0.242 & 0.039 & -0.097 \\
14 & 0.134 & -0.262 & -0.471 & -0.063 & 0.262 & -0.185 \\
15 & -0.027 & -0.077 & -0.340 & -0.020 & 0.307 & -0.031 \\
16 & 0.328 & -0.138 & 0.126 & 0.388 & -0.086 & 0.124 \\
18 & -0.213 & 0.214 & -0.024 & 0.680 & 0.457 & 0.223 \\
19 & -0.474 & 0.384 & & & -0.242 & -0.111 \\
20 & & 0.222 & 0.466 & 0.258 & & 0.315 \\
21 & 0.039 & & & -0.867 & & -0.414 \\
22 & -0.066 & & 0.200 & -0.296 & & -0.054 \\
23 & -0.296 & & 0.586 & & & 0.145 \\
32 & & & 0.211 & & & 0.211 \\
33 & 0.474 & & & & & 0.474 \\
34 & 0.018 & & & & 0.351 & 0.184 \\
35 & 0.229 & -0.244 & -0.0005 & -0.206 & 0.278 & 0.011 \\
time mean & 0.070 & -0.379 & 0.038 & 0.197 & -0.138 & -0.042 \\
std & 0.054 & -0.064 & 0.002 & -0.047 & 0.137 & 0.037 \\
width (deg N lat) & 0.272 & 0.256 & 0.330 & 0.400 & 0.222 & 0.214 \\
\hline
\end{tabular}

Table 4.7: Height changes across ascending tracks, in meters 

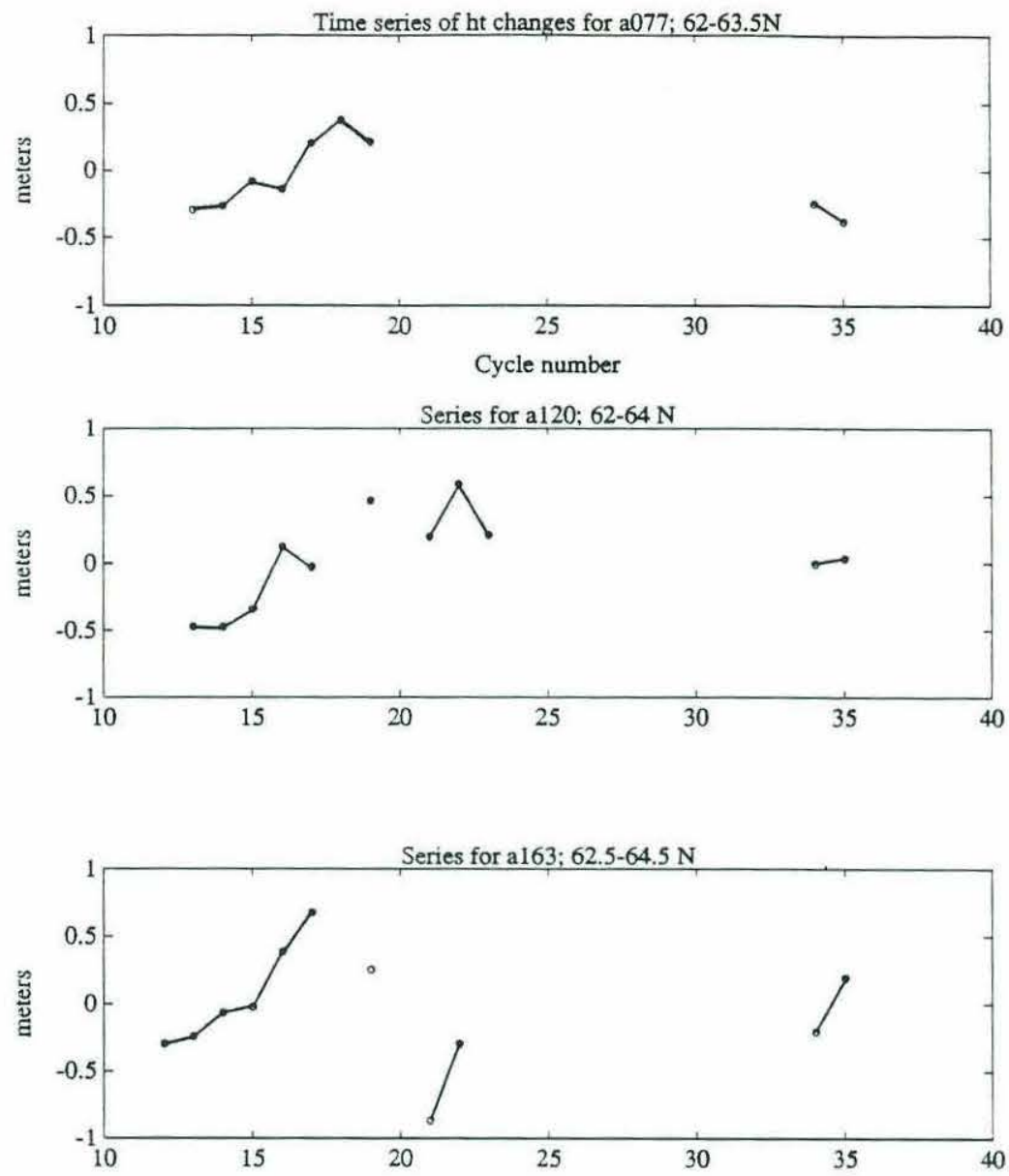

Figure 4-12: Time series of height changes along subtracks a077, a120 and a163. Between cycle12 and 17 the series exhibit a trend toward positive height change.

one or two orbits. These values are not considered as robust as the mean values for cycles 12 through 19 which represent three or more passes of data. The largest height change, $-0.867 \mathrm{~m}$, occurred along track a163 during the fall of 1987 . Lack of data along three of the other tracks precludes support of the anomalously high value, and the value along the fifth track appears quite different. Differences in the slopes of height residuals between the five subtracks may not correspond to differences in actual slopes because different repeat cycles and a different number of repeat cycles are available along each subtrack to compute the mean, creating different mean slopes. Therefore, comparing the time series of height changes along each subtrack proved to be an easier method of evaluating the data for general trends (Figure 4-12 and Figure 4-13.) Although 

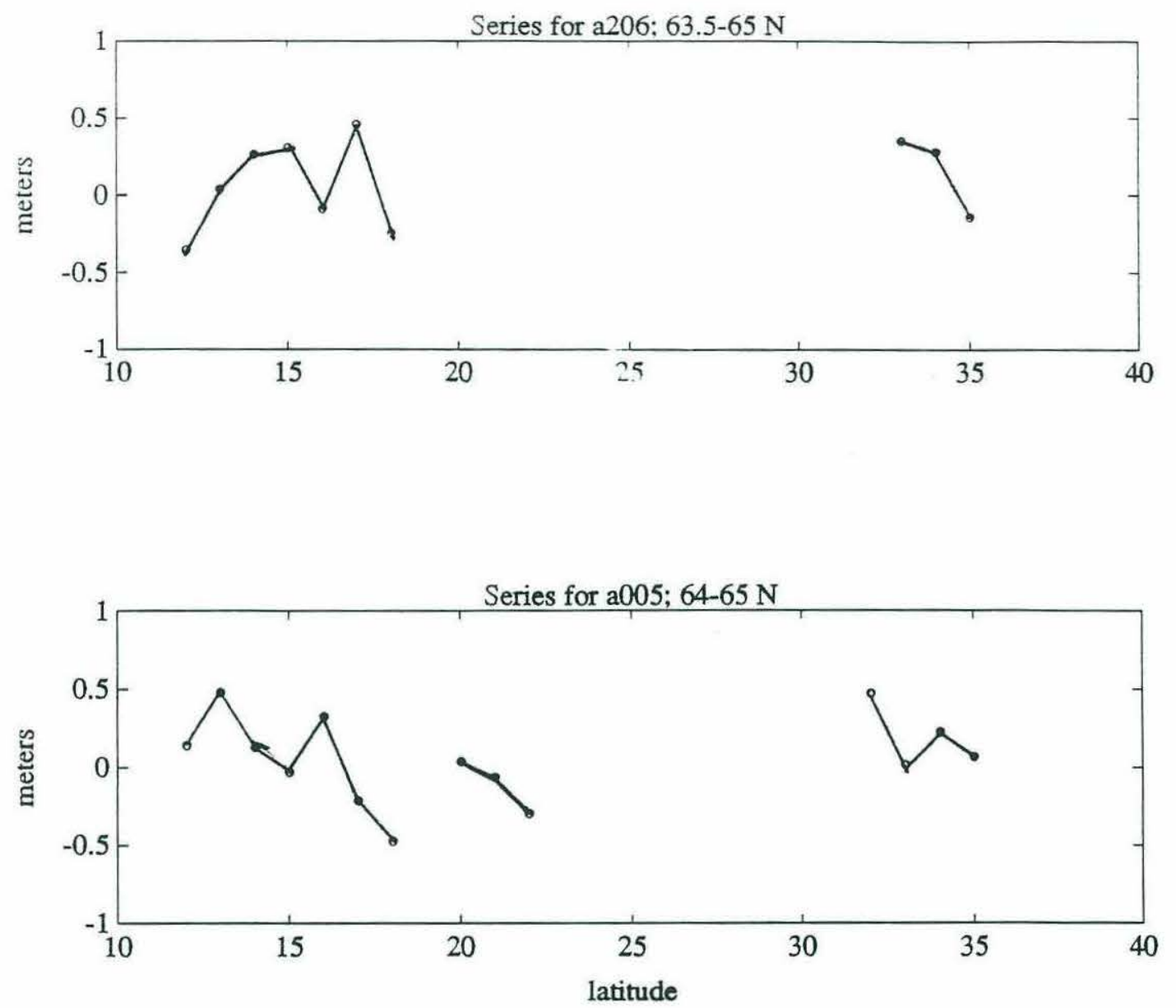

Figure 4-13: Time series of height changes along subtracks a206 and a005. Only track a005 does not exhibit the positive trend between cycles 12 and 17 . 
the data are sparse, the series reveal an average trend toward larger, positive height changes between cycles 12 and 17, indicating a decrease in northward flow intensity during the summer and early fall of 1987 . Track a005 is the exception, possibly because of its location near the upper coast of the Gulf of Anadyr and the turning point of the current, and the smaller width over which the height change was calculated. This is consistent with a decrease in the Bering slope current transport (Figure 4-10 for the same cycles). The analysis of the Bering Slope current and the western boundary current qualitatively supported the proposed pattern of western circulation by Kinder et al. What remained was confirmation of the flows' ability to supply a major part of the Bering Strait transport. Studies of the Bering Strait transport through 1973 reported an average northward transport of $1.5 \mathrm{~Sv}$ (Coachman and Aagaard, 1981). This estimate, however, was based on current station sections representing primarily summer conditions. Coachman and Aagaard's 1981 reevaluation of more recent (19761977) observations revealed significant southward flow events not included in the earlier analysis because they occurred primarily during the winter months. The result of including these southward events was a reduced annual mean transport of $0.8 \pm 0.2 \mathrm{~Sv}$. The original $1.5 \pm 0.4 \mathrm{~Sv}$ estimate was retained for this examination, however, because the western boundary current height fluctuations from GEOSAT were available only for the summer-early fall season. With this estimate, three sets of information were available at three separate locations in the northwestern Bering Sea. The parameters and values available at each location are displayed on the map in Figure 4-14.

\section{Mean Flow Examination}

If the Bering slope current supplies only the western boundary current, which in turn provides the majority of the flow through the Bering Strait, the Bering slope current must subsequently provide a transport roughly equivalent to that through the strait, or

$$
<T_{B S}>=\frac{g}{f} D_{B S C}<\Delta h_{B S C}>
$$

where $\left\langle T_{B S}>\right.$ is the average summer transport through the Bering Strait (BS), g is acceleration due to gravity, $\mathrm{f}$ is the coriolis parameter based on a mean latitude of 


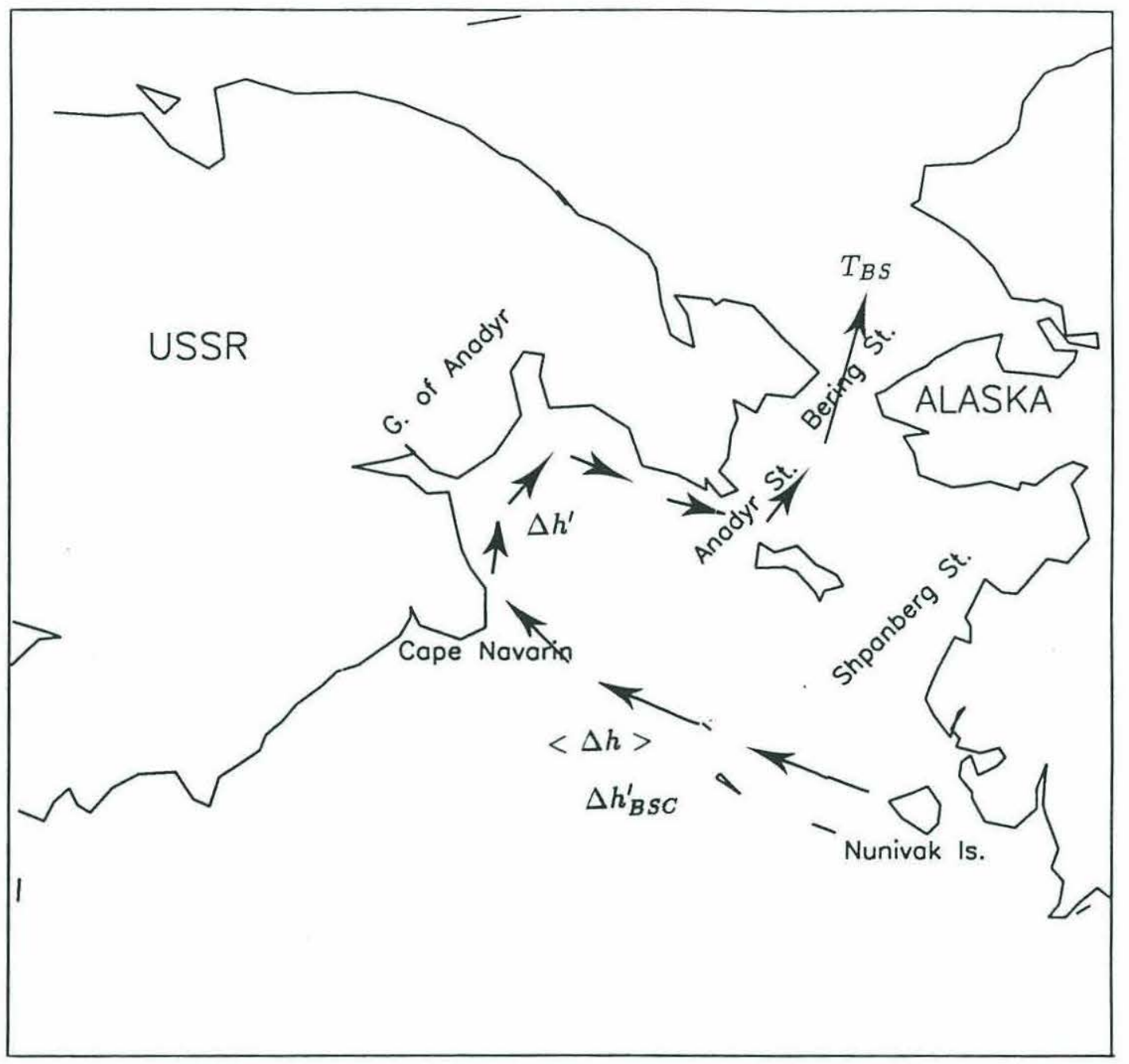

Figure 4-14: Map depicting the information available on the circulation pattern in the northwestern Bering Sea. $T_{B S}$ is transport through the Bering Strait, $1.5 \pm 0.4$ Sv; height fluctuations across the western boundary current are represented by $\Delta h^{\prime}$; parameters in the Bering slope current include a mean height change $\langle\Delta h\rangle$, height fluctuations and seasonal height changes. 
$59^{\circ}, D_{B S C}$ is the scale depth of the Bering slope current (BSC) assuming a baratropic current, and $\left\langle\Delta h_{B S C}\right\rangle$ is the absolute height difference across the BSC. Using 1.5 $\mathrm{Sv}$ for mean transport and $0.596 \mathrm{~m}$ for the height difference results in a scale depth of approximately $32 \mathrm{~m}$. This scale depth indicates that the BSC, located in depths of $170 \mathrm{~m}$, is somewhat surface intensified, with most activity occuring in the top $32 \mathrm{~m}$. Because no mean height estimate was available across the western boundary current (WBC), no mean calculation could be performed.

\section{Analysis of Fluctuations}

By the same argument as above, a slope current scale depth was again computed. This time the value represented the depth required for the height fluctuations across the BSC to account for the fluctuations in transport through the Bering Strait $(0.4 \mathrm{~Sv})$. The height fluctuations, $\Delta h_{B S C}^{\prime}$, were calculated as the sample standard deviation of $\Delta h$ for all repeat passes, a value of $0.124 \mathrm{~m}$. $D_{B S C}$ was estimated at approximately 41 $\mathrm{m}$, comparable to the scale depth calculated previously. In a similar fashion, a scale depth for the WBC was calculated to be approximately $24 \mathrm{~m}$, in a total depth of 75 to $100 \mathrm{~m}$. To this point, both depth values seem reasonable, or at least consistent: the scale depth of the WBC is just over half that of the BSC, in a total water depth that is likewise just over half that of the BSC.

\section{Seasonal Analysis}

Figure 4-15 compares the time series of height across the WBC with the time series of absolute height across the slope current. On each plot the dotted line represents the best linear fit to the data points between cycles 10 and 19 inclusive. The positive trend of the data in the top plot reflects the decrease in northward flow discussed earlier. This flow trend is echoed in the bottom plot by a decrease in absolute height across the BSC over the same time period. The remaining question is whether or not the magnitudes of change are comparable. From the slope of the fit to the WBC data in the top plot, the change across the boundary current for this time period (late spring to early fall) is given as $0.056 \mathrm{~m}$, resulting in a transport decrease of $0.11 \mathrm{~Sv}$. To account 

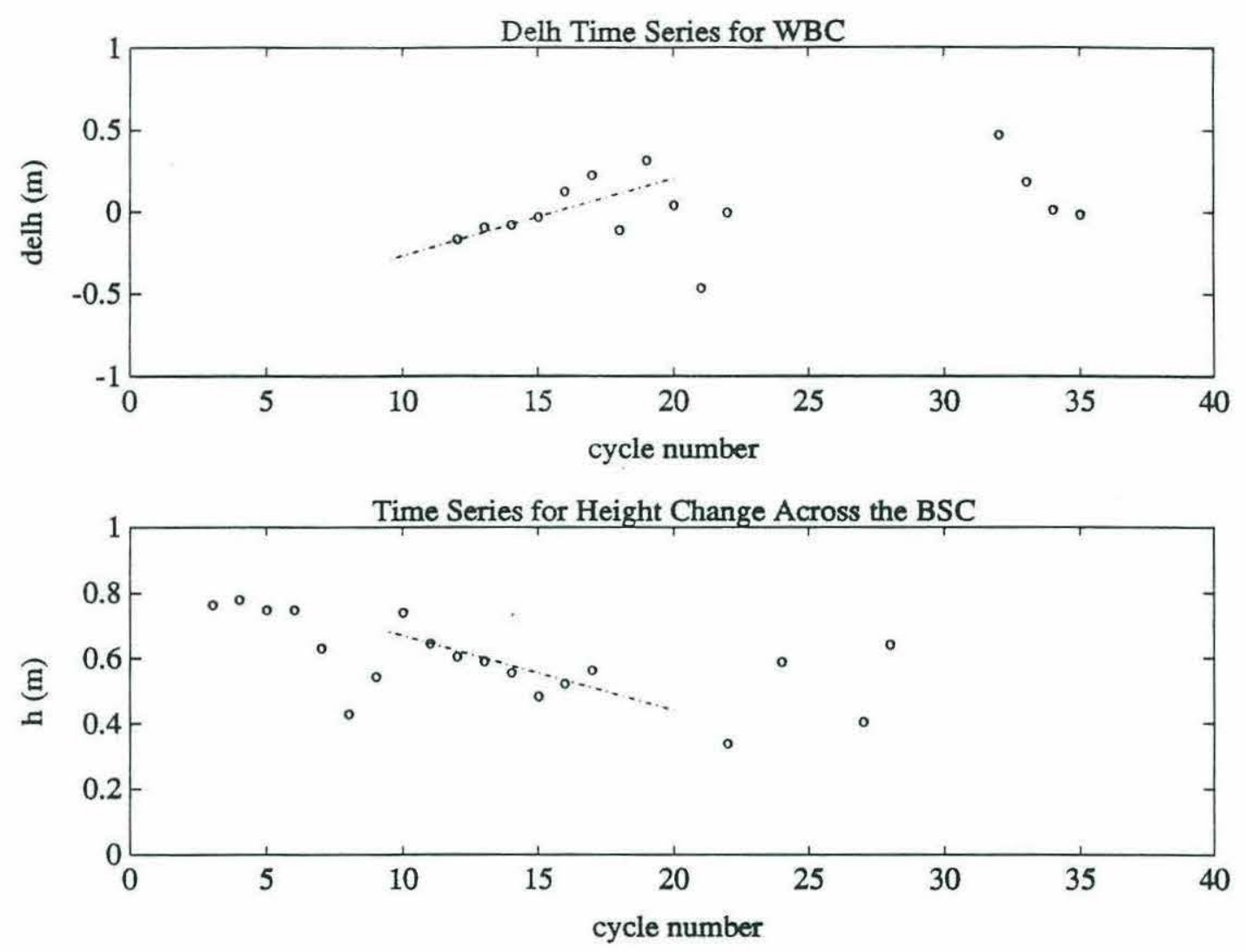

Figure 4-15: Time series of height changes across the WBC are plotted in top graph, and absolute height across the BSC in the bottom graph. The dotted lines in each represent the best linear fit to the data between cycles 10 and 19 . 
for such a change, the required decrease in height across the BSC (using the calculated scale depth of $41.0 \mathrm{~m}$ ) is approximately $0.034 \mathrm{~m}$. The actual height drop given by the slope of the linear fit is approximately $0.028 \mathrm{~m}$, a comparable value. In summary, the Bering slope current appears to be about twice as deep as the western boundary current, with height fluctuations of only half the size of those in the boundary current. These values provide transport values consistent with the hypothesis that the entire BSC turns northward into the Gulf of Anadyr instead of separating where it meets the coast. The scale depth values for each current are feasible in view of the total water depths in which they occur. The height fluctuations and depths calculated for the two currents are also consistent with values required to account for transport changes through the Bering Strait. 


\section{Chapter 5}

\section{Summary and Conclusions}

An analysis of the major circulation patterns in the Bering Sea, with a focus on the western half of the sea, was undertaken using a collinear analysis of GEOSAT data. Seventy sets of up to 35 repeat cycles were processed to produce digitized maps of sea surface height variability in the Bering Sea. The weighted regression for computing a parabolic orbit error was found to effectively reduce geoid contamination over regions of strong geoid gradient such as the Aleutian trench. The composite map of variability for descending subtracks revealed a region of higher variability coincident with the location of the Bering slope current. Similarly, the map of variability for ascending subtracks depicted a region of activity along the proposed flow path of a western boundary current. Surprisingly, no evidence was found in either map of the expected bifurcation of the Bering slope current at Cape Navarin into two opposite flows. Instead, it is assumed to flow northward into the Gulf of Anadyr, where it becomes the western boundary current. Higher regions of variability were also discovered along the southeastern coastal stretches. These regions are known to have large amplitude tides, so that the variability there does not necessarily indicate coastal currents. While an analysis of the Schwiderski ocean tide correction along both ascending and descending tracks proved to be a sensible correction, it is not considered reliable below depths of approximately $100 \mathrm{~m}$. Because this research focused on the western circulation pattern, no futher analysis of the southeastern regime was made. Analysis of the Bering slope current using a Gaussian velocity profile produced a mean maximum velocity of 
$0.788 \mathrm{~ms}^{-1}$ and a surface transport of $0.477 \times 10^{5} \mathrm{~m}^{2} \mathrm{~s}^{-1}$, revealing it to be somewhat stronger and narrower than expected. Parameterizations of the Bering slope current and western boundary current supported the hypothesis that the Bering slope current flows northwestward toward Cape Navarin, where it turns northward into the Gulf of Anadyr and forms the western boundary current. The western boundary current, in turn, maintains a northward flow large enough to supply a major percentage of the 1.5 Sv estimated to flow through the Bering Strait during the summer season.

Historically, the advantage of altimeter data over traditional shipboard measurements has been the high spatial and temporal density of the measurements. This density enables synoptic scale coverage of the oceans without the cost, difficulty and limitations inherent in conventional shipboard techniques. In the Bering Sea the limitations on in situ observations are even more severe, particularly in the northern and western regions, because of diplomatic considerations and inaccessibility due to ice coverage throughout a large portion of the year. Unfortunately, many meteorological and oceanographic conditions that make the region inaccessible to ships also make analysis of altimeter data more difficult. Regions such as the Bering Sea have typically been avoided in altimeter analyses for several reasons: 1) the signal to noise ratio is low; 2) the ice coverage causes gaps in data; 3 ) the sea is land-enclosed, causing altimeter lock problems; 4) fifty percent of the sea consists of water depths less than $50 \mathrm{~m}$, making tidal contribution difficult to analyze, model and eliminate. In view of the above limitations, this analysis of altimeter data was very successful in providing information on regions of the Bering Sea where previously there was little or verifying a proposed pattern of circulation. 


\section{Bibliography}

Born, G.H., M.E. Parke, and B.D. Tapley, 1982: The SEASAT Altimeter Data and its Accuracy Assessment. Journal of Geophysical Research. 87 (C5), 3179-3188.

Calman, J., 1987: Introduction to Sea-surface Topography from Satellite Altimetry. Johns Hopkins APL Technical Digest. 8 (2), 206-211.

Campbell, J.W., 1988: Evaluation of GEOSAT Data and Application to Variability of the Northeast Pacific Ocean. M.S. thesis, 163 pp., Woods Hole Oceanographic Institution and Massachusetts Institute of Technology.

Caruso, M. and C. Dunn, 1989: Satellite Data Processing System (SDPS) Users Manual V1.0. Woods Hole Oceanog. Inst. Tech Rept., WHOI-89-13. 58 pp., Woods Hole, MA.

Cheney, R.E., B.E. Douglas, and L.L. Miller, 1988: Evaluation of GEOSAT Altimeter Data with Application to Tropical Pacific Sea Level Pacific Sea Level Variability. Submitted to Journal of Geophysical Research - Oceans. Cheney, R.E., B.E. Douglas, R.W. Agreen, L.L. Miller, and D.L. Porter, 1987: GEOSAT Altimeter Geophysical Data Recored (GDR) user handbook. Rockville, MD: NOAA National Ocean Service.

Cheney, R.E., J.G. Marsh, and B.D. Beckley, 1983: Global Mesoscale Variability from Collinear Tracks of SEASAT Altimeter Data. Journal of Geophysical Research. 88 (C7), 4343-4354.

Coachman, L.K. and K. Aagaard, 1981: Reevaluation of Water Transports in the Vicinity of Bering Strait. In The Eastern Bering Sea Shelf: Oceanography and Resources, edited by D.H. Hood and J.A. Calder, 95-110. University of Washington Press.

Douglas, B.C. and R.E. Cheney, 1981: Ocean Mesoscale Variability From Repeat Tracks of Geos-3 Altimeter Data. Journal of Geophysical Research. 86 (C11), 10931-10937.

Flament, P., 1988: Preliminary Analysis of GEOSAT Altimeter Data over the Coastal Transition Zone Off California. Coastal Transition Zone Newsletter. $2(2)$, 
Jones, S.C., B.E. Tossman, and L.M. Dubois, 1987: The GEOSAT Ground Station. Johns Hopkins APL Technical Digest. 8 (2), 190-196.

Kelly, K.A. and S.T. Gille, 1989: Gulf Stream Surface Transport and Statistics fromthe GEOSAT Altimeter. Journal of Geophysical Research (In press). Kinder, T.H., D.C. Chapman, and J.A. Whitehead, Jr., 1986: Westward Intensification of the Mean Circulation on the Bering Sea Shelf. Journal of Physical Oceanography. 16 (7), 1217-1229.

Kinder, T.H. and J.D. Schumacher, 1981: Circulation Over the Continental Shelf of the Southeastern Bering Sea. In The Eastern Bering Sea Shelf: Oceanography and Resources, edited by D.H. Hood and J.A. Calder, 53-77. University of Washington Press.

Marsh, J.G. and E.S. Change, 1978: 5' Detailed Gravimetric Geoid in the Northwestern Atlantic Ocean. Journal of Marine Geodesy. 1 (3), 253-261. Mofjeld, H.O., 1975: Empirical Model for Tides in the Western North Atlantic Ocean. NOAA Technical Report ERL 340-AOML 19. 24 pp., U.S. Department of Commerce, Boulder, CO.

Mofjeld, H.O., 1984: Recent Observations of Tides and Tidal Currents from the Northeastern Bering Sea Shelf. NOAA Technical Memorandum ERL PMEL-57. 36pp., Pacific Marine Environmental Laboratory, Seattle, WA. Mofjeld, H.O., 1986: Observed Tides on the Northeastern Bering Sea Shelf. Journal of Geophysical Research. 91 (C2), 2593-2606.

Niebauer, H.J., 1981: Recent Fluctuations in Sea Ice Distribution in the Eastern Bering Sea. In The Eastern Bering Sea Shelf: Oceanography and Resources, edited by D.H. Hood and J.A. Calder, 133-140. University of Washington Press.

Overland, J.E. and A.T. Roach, 1987: Northward Flow in the Bering and Chukchi Seas. Journal of Geophysical Research. 92 (C7), 7097-7105.

Pearson, C.A., H.O. Mofjeld, and R.B. Tripp, 1981: Tides of the Eastern Bering Sea Shelf. In The Eastern Bering Sea Shelf: Oceanography and Resources, edited by D.H. Hood and J.A. Calder, 111-130. University of Washington Press.

Sayles, M.A., K. Aagaard, and L.K. Coachman, 1979: Oceanographic Atlas of the Bering Sea Basin. Seattle: Universit of Washington Press. 
Schwiderski, E.W., 1980: On Charting Clobal Ocean Tides: Reviews of Geophysics and Space Physics. 18 (1), 243-268.

Stewart, R.H., 1985: Methods of Satellite Oceanography. Berkeley: University of California Press, 248 pp.

Tai, C.K. and L.L. Fu, 1986: On Crossover Adjustment in Satellite altimetry and its Oceanographic Implications. Journal of Geophysical Research. 91 (C2), 2549-2554.

Thompson, J.D., G.H. Born, and G.A. Maul, 1983: Collinear-Track Altimetry in the Gulf of Mexico from SEASAT: Measurements, Models and Surface Truth. Journal of Geophysical Research. 88 (C3), 1625-1636.

Zwally, H.J., J.A. Major, A.C. Brenner, and R.A. Bindschandler, 1987: Ice Measurements by GEOSAT Radar Altimetry. Johns Hopkins APL Technical Digest. 8 (2), 251-254. 